ASYMMETRIC COLLATERAL REQUIREMENTS AND OUTPUT COMPOSITION

- scar Arce jose Manuel campa. and Anger Gavilán.

Documentos de Trabajo N. 0837

BANCO E ESPANA

Eurosistema

\section{8}

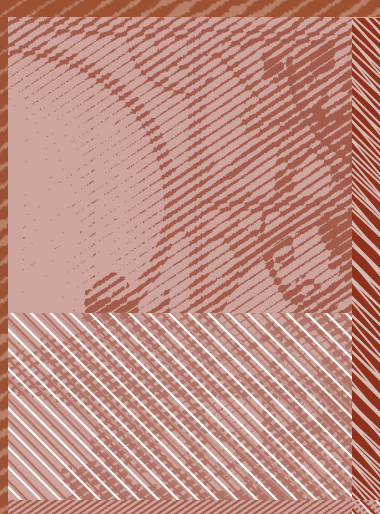

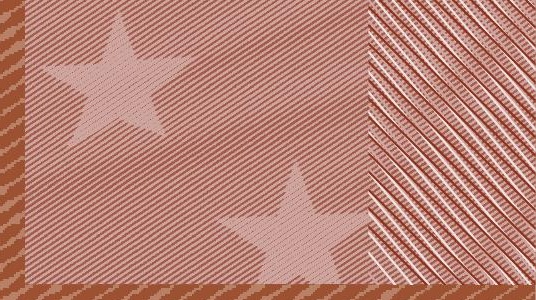
. 


\title{
ASYMMETRIC COLLATERAL REQUIREMENTS AND OUTPUT COMPOSITION ${ }^{(*)}$
}

\author{
Óscar Arce ${ }^{(* *)}$ \\ BANCO DE ESPAÑA \\ José Manuel Campa ${ }^{(* *)}$ \\ IESE BUSINESS SCHOOL \\ Ángel Gavilán ${ }^{(* * *)}$ \\ BANCO DE ESPAÑA
}

${ }^{(*}$ We thank the editor, Enrique Alberola, an anonymous referee and seminar participants at the Bank of Spain and FEDEA for helpful comments and suggestions. The opinions expressed here are solely those of the authors and do not necessarily reflect the views of the Bank of Spain or the Eurosystem.

(*) Bank of Spain, Research Department. E-mail: o.arce@bde.es.

${ }^{(* \star)}$ IESE Business School. E-mail: JCampa@iese.edu.

$\left(^{\star \star \star \star}\right)$ Bank of Spain, Research Department. E-mail: angel.gavilan@bde.es. 
The Working Paper Series seeks to disseminate original research in economics and finance. All papers have been anonymously refereed. By publishing these papers, the Banco de España aims to contribute to economic analysis and, in particular, to knowledge of the Spanish economy and its international environment.

The opinions and analyses in the Working Paper Series are the responsibility of the authors and, therefore, do not necessarily coincide with those of the Banco de España or the Eurosystem.

The Banco de España disseminates its main reports and most of its publications via the INTERNET at the following website: http://www.bde.es.

Reproduction for educational and non-commercial purposes is permitted provided that the source is acknowledged.

(C) BANCO DE ESPAÑA, Madrid, 2008

ISSN: 0213-2710 (print)

ISSN: 1579-8666 (on line)

Depósito legal:

Unidad de Publicaciones, Banco de España 


\section{Abstract}

This paper studies how investment and production in an economy is allocated across sectors when they face asymmetric financial conditions. Namely, when investors in one sector may run projects with higher loan-to-values than in another sector. Investors decide where to invest based on total rents and face a trade-off. While they may run larger projects in the sector with the best financial conditions, unit rents in this sector are lower than in the other sector due to a pledgeability premium. The level of interest rates affects this trade-off and therefore investors' endogenous segmentation across sectors. The effect is non-monotonic. When interest rates are high, projects are small and the differences in unit rents across sectors dominate the differences in project sizes. In this case, a drop in interest rates, move investors toward the most productive sector. Instead, when interest rates are low, projects are large, but much larger in the sector with the best financial conditions. In this case, the differences in project sizes across sectors dominate the differences in unit rents and a drop in interest rates moves investors towards the least productive sector but with the best access to external funding. We find that this hump-shaped relationship between interest rates and the share of investors allocated to a given sector may translate into a similar hump-shaped relationship between interest rates and the ratio of aggregate investment across sectors. Instead, in a model without financial asymmetries across sectors both relationships are monotonic and do not exhibit a hump. We claim that this paper provides helpful insights to understand the pattern of sectoral reallocation of investment and production observed in some OECD countries recently.

Keywords: Investment and credit, pledgeability premium, collateral constraints, sectoral allocation, housing.

JEL Classification Numbers: E22, E32, E44. 


\section{Introduction}

Financial leverage and the ability of the financial sector to allocate financing to investment opportunities is one of the key determinants of a well-functioning economic system. Recent historical experience suggests that monetary conditions and the functioning of the financial system may affect not only the level of investment in an economy but also the allocation of that investment within different sectors.

The purpose of this paper is to study how investment and production are allocated across sectors in an economy in which entrepreneurs face financing constraints that differ depending on the project they choose to pursue. We consider two sectors, one producing a durable non-tradeable good (housing) and another one producing a non-durable tradeable good (consumption). These sectors differ in their ability to obtain financing. In particular, we consider that investors in the housing sector, because they offer better collateral to financial institutions, are able to run projects with higher loan-to-value ratios than those of investors in the consumption sector. ${ }^{1}$ A minimum investment requirement in the projects of both sectors further highlights this financial asymmetry.

This assumption appears to be consistent with the evidence across a wide range of countries. Figure 1 shows the capital structure (measured as the ratio of debt to total assets) of construction firms (line with squares) and manufacturing firms (line with circles) across a broad range of Euro area countries for the period 1995-2004 (except for Finland, where data go from 1999 to 2004). Construction firms have consistently been in all countries and through out the time period more leveraged than manufacturing firms, suggesting that the construction sector have a higher access to debt relative to the value of its assets than other activities.

\footnotetext{
${ }^{1}$ One could argue, for instance, that production in the consumption goods sector is, relative to the production in the housing sector, more intensive in human capital than in physical assets and that, as implicitly assumed in most of the literature studying consumers' borrowing, due to moral hazard issues in borrower's human capital, this has less value as collateral than physical assets.
} 
Austria

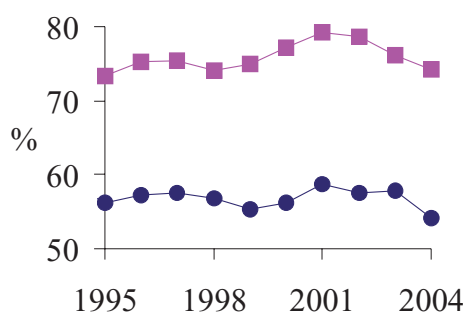

France

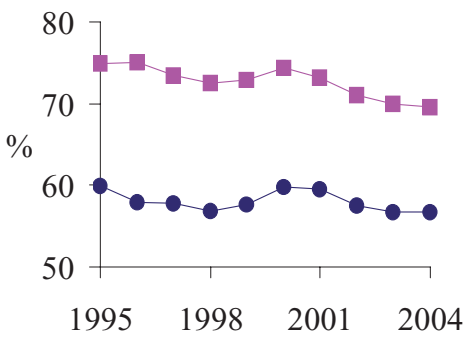

Netherlands

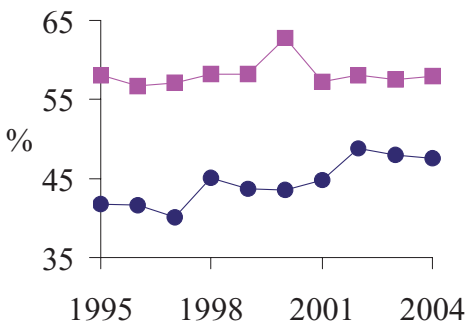

Belgium

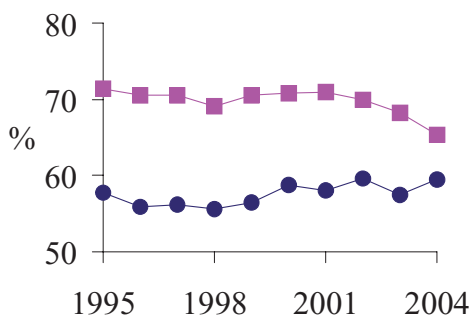

Germany

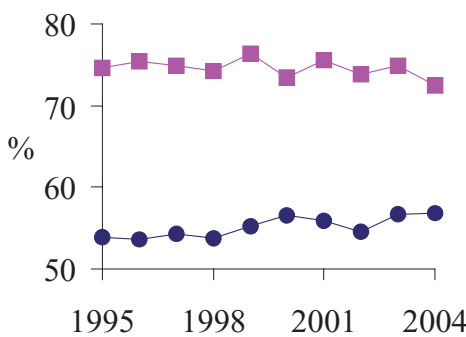

Portugal

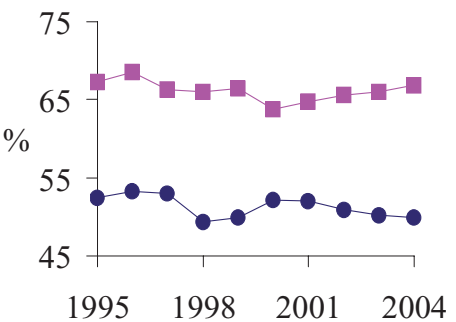

Finland

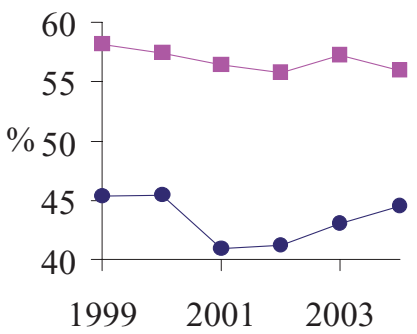

Italy

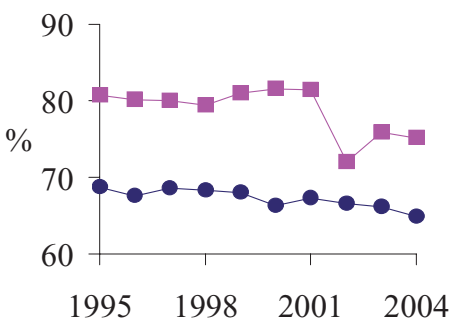

Spain

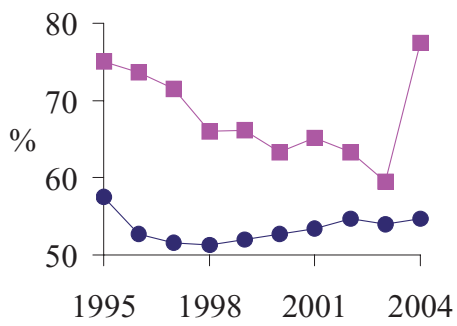

Figure 1. Ratio of debt to total assets of construction and manufacturing firms. ${ }^{2}$

In the model, a first consequence of this financial asymmetry across sectors is that, in any interior equilibrium where production in both sectors is undertaken, a pledgeability premium arises in the sense that, due to the higher pledgeability of housing projects, these must necessarily offer lower unit rents. Hence, optimizing investors face a trade-off between lower unit rents but larger projects in the housing sector and larger unit rents but smaller projects in the consumption sector.

This trade-off is affected by the level of the interest rate in the economy. When interest rates are relatively high, projects in both sectors are small and differences in unit rents across sectors

${ }^{2}$ Data comes from the BACH database published by the European Commission. For details on the database see Drudi et al. (2007). 
dominate. Every investor who can reach the minimum investment size in the consumption sector optimally decides to invest there. Intuitively, for these rates, the investors' allocation across sectors is driven by feasibility. On the contrary, when interest rates are low, projects in both sectors are large. However, due to the better financial conditions in the housing sector, projects may be much larger in this sector than in the consumption one. In this case, the relative differences in project sizes between sectors dominate the relative differences in unit rents and some investors who can afford investing in the consumption sector prefer to invest in housing where they can obtain larger rents by running much larger projects. Intuitively, for these rates, feasibility does not play any role and profitability drives the investors' equilibrium segmentation.

The effect of interest rates on the investors' equilibrium allocation is non-monotonic. When that allocation is driven by feasibility, a drop in interest rates alleviates the investors' feasibility constraint and allows some investors to leave the housing sector towards the consumption goods sector. Instead, when investors' segmentation across sectors is driven by profitability, a drop in interest rate reinforces the effect of the better financial conditions in the housing sector and leads to a reallocation of investors towards that sector. As a result, the relationship between interest rates and the equilibrium share of investors in the consumption sector is hump-shaped.

But changes in interest rates in this model not only affect the investors' endogenous segmentation across sectors (the extensive margin). They may also lead to large reallocations of aggregate investment and productive capacity in the economy and to large changes in the relative price of goods, the stock of foreign debt and aggregate productivity. In particular, we show that the hump-shaped relationship between interest rates and the investors' endogenous segmentation may translate into a similar hump-shaped relationship between interest rates and the ratio of aggregate investment in the consumption sector relative to the housing sector. Interestingly, a model that considers symmetric financial conditions across sectors can not generate none of these non-monotonic relationships.

We believe the features in this model can help in understanding some recent episodes of investment allocation and lending across sectors in a large number of OECD countries. The hump-shaped relationship between interest rates and industry investment arising from the model is a pattern observed in the data. Figure 2 shows for a number of OECD countries the relationship between the ratio of investment allocated to non-construction activities relative to construction activities (housing and other construction) and the level of real interest rates for the period 1995-2005. There appears to be a nonlinear hump-shaped relationship. Construction investment accounted for a larger share of overall investment in these economies when interest rates were very low and when interest rates were high. For an intermediate range of interest rates the share of non-construction investment was relatively higher. ${ }^{3}$

\footnotetext{
${ }^{3}$ We do not claim that this observed pattern is driven exclusively by the mechanism highlighted in this paper.
} 
Canada

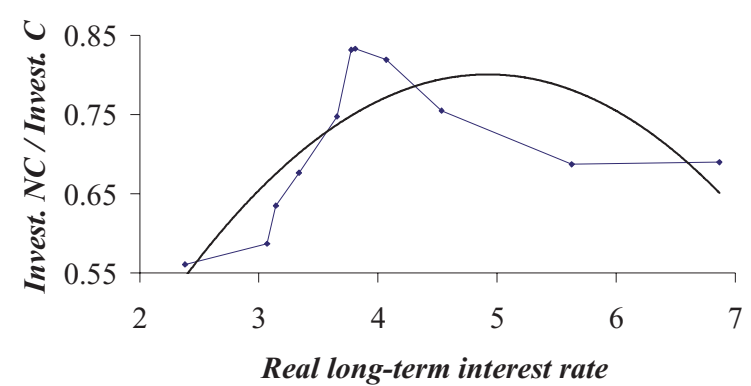

Italy

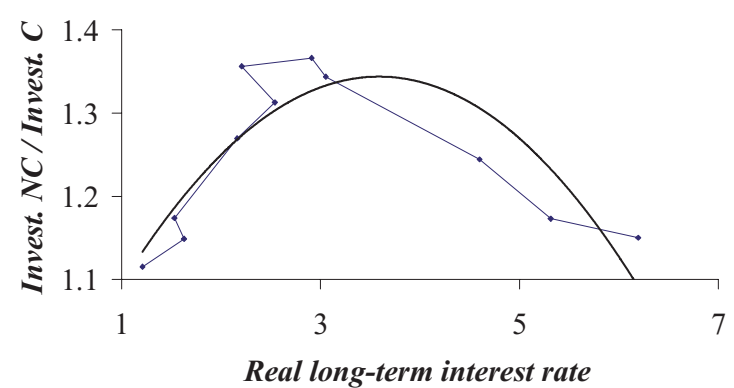

Spain

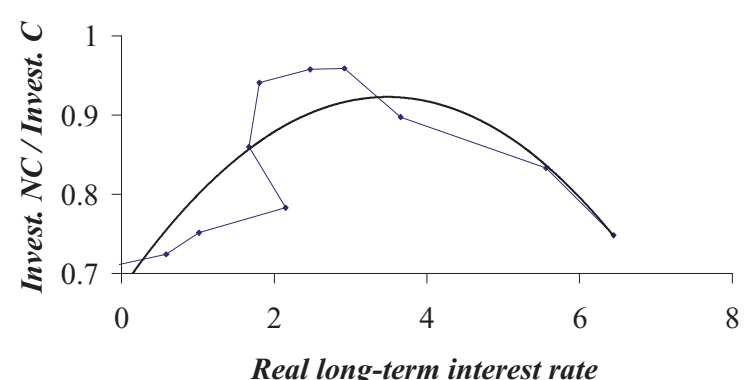

$\boldsymbol{U K}$

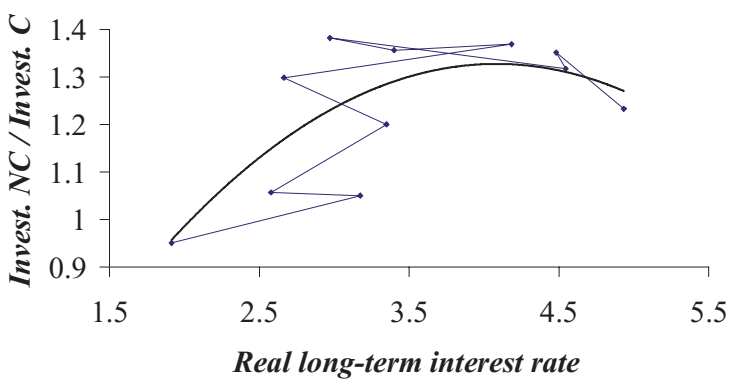

France

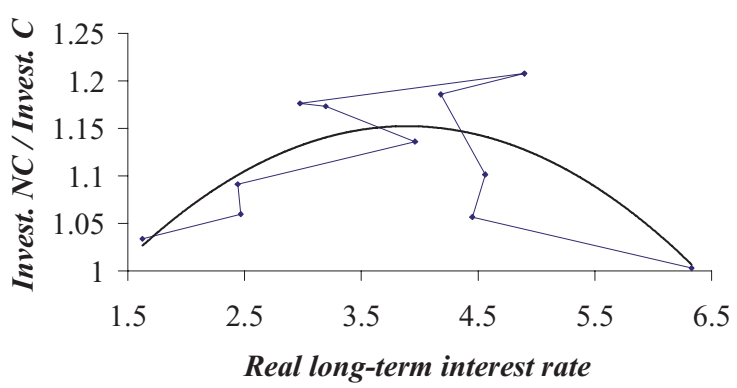

Netherlands

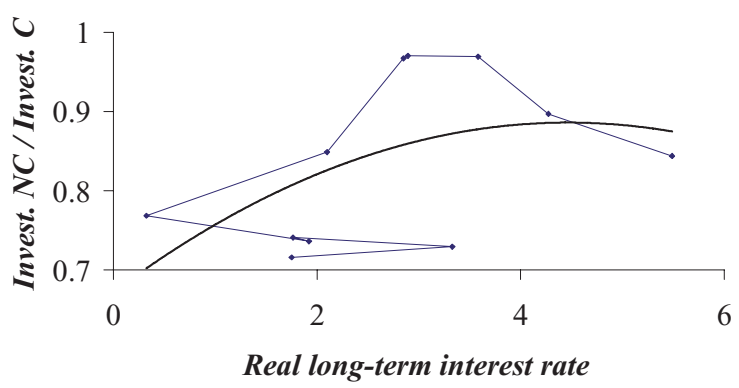

Sweden

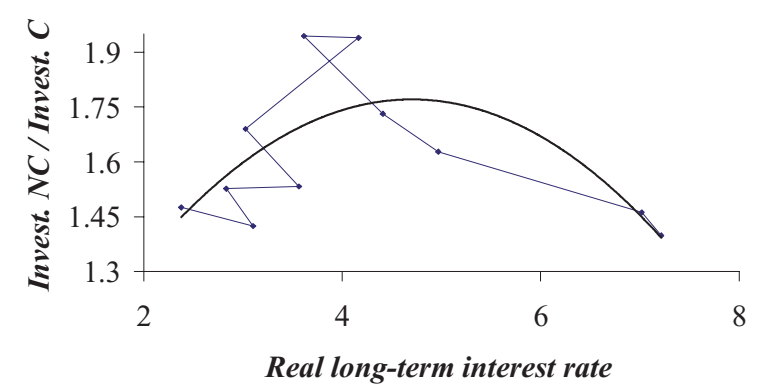

$\boldsymbol{U S A}$

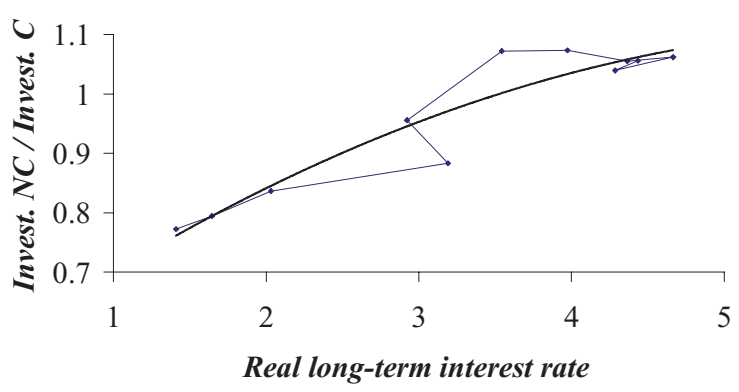

Figure 2. Investment across sectors and interest rates. ${ }^{4}$

Just that it goes in line with the predictions of our model. In this sense, we acknowledge that many other factors not included in this model can potentially be helpful in explaining the evidence shown in Figure 2.

${ }^{4}$ Data for real long-term interest rates come from the OECD Economic Outlook No. 80 (December 2006). Investment data come from the OECD Annual National Accounts Main Aggregates. The dark lines in the figure 
Our model is most closely related to Matsuyama (2007a) who analyses what happens to the supply side of an economy when producers must choose among projects with different degree of pledgeability. Matsuyama shows that credit cycles and credit traps can endogenously result in an economy of this type. However, that paper only considers a one sector economy (all projects produce the same output) and it is not able to say anything about the sectoral reallocation of investment induced by shocks in the presence of asymmetric financial conditions. This is precisely the purpose of this paper.

Our paper is also related to Antràs and Caballero (2007) who consider asymmetric financial conditions, not only across sectors in an economy, but also across countries. They develop a general equilibrium model including these financial frictions and analyze how they affect trade and capital flows between South and North. Our approach is different. We focus on a small open economy and we are mostly concerned with the macroeconomic impact that falls in the exogenous interest rate have on the economy.

The rest of the paper is organized as follows. Section 2 presents the model. Section 3 describes the different steady state equilibria that may exist in this economy and how they depend on the interest rate. Section 4 provides some comparative statics via numerical examples and it shows how the model performs when interest rates change or the degree of financial asymmetries diminishes. Section 5 concludes and provides some lines for further research.

\section{The model}

We consider a small open economy with two goods, a tradeable and a non-tradeable. The tradeable good is perishable and its price, which is normalized to 1 , is taken as given by all domestic agents. The non-tradeable good is durable and it depreciates at a rate $\delta<1$. Its price is determined in the domestic market. We, henceforth, refer to the tradeable and the non-tradeable good as consumption and housing, respectively.

This economy is populated by a continuum of agents who live for two periods. There are three type of agents: investors, consumers and housing intermediaries. We next deal with each of them separately.

\section{$2.1 \quad$ Investors}

A measure 1 of investors is born every period. In the first period of their life, investors are endowed with one unit of consumption goods and decide on how to invest it. They face three different alternatives for investment. First, they may lend their endowment in the international fit the data (blue lines) using a second order polynomial. 
credit market, earning a gross risk-free return of $R_{t}$. Second, they may invest in the production of consumption goods using a constant-returns-to-scale (CRS) technology that produces $A^{c}$ units of consumption goods at $t+1$ per unit invested at $t$. Third, they may invest in the production of houses using a CRS technology that produces $A^{h}$ housing units at $t+1$ per unit of consumption good invested at $t .{ }^{5}$ Investors can not run more than one project simultaneously.

Lending does not require a minimum volume of investment. Instead, investment in the production of houses and consumption goods is subject to minimum scale requirements. No investor can run any project in either sector unless he is able to make an investment of size $m$ or larger. Hence, the following feasibility constraint applies to all investments in the housing and consumption sectors,

$$
x_{t} \geq m,
$$

where $x_{t}$ is the size of the investment. In order to rule out the trivial case in which (1) never binds we assume that $m>1$. That is, the initial endowment is not sufficient to overcome the above feasibility constraint. Rather, investors must rely on external funding, paying an interest rate $R_{t}$ (denoted in gross terms) for borrowed funds. As it will be clear below, this minimum size requirement is key in determining the allocation of investors across sectors and its importance depends on the interest rate. The fact that $m$ is the same in the $C$ and $H$ sectors is just a simplifying assumption.

Denoting by $d_{t}$ the volume of borrowed $\left(d_{t}>0\right)$ or lent $\left(d_{t}<0\right)$ funds, the budget constraint for a young investor is given by

$$
x_{t} \leq 1+d_{t}
$$

Borrowing is subject to borrowing constraints that limit the maximum volume of external funding per project. In particular, we assume that any investor in housing at $t$ can not borrow more than a fraction $\theta^{h}<1$ of the discounted market value of his production at $t+1$. Formally,

$$
d_{t} \leq \theta^{h} P_{t+1} y_{t+1}^{h} / R_{t}
$$

where $P_{t+1}$ is the unit price of housing, in terms of consumption goods, at $t+1$ and $y_{t+1}^{h}$ is the physical output generated by the project, i.e. $y_{t+1}^{h}=A^{h} x_{t}$. Similarly, we impose a borrowing limit to investors in the $C$ sector. In particular, each investor in this sector faces a borrowing limit of the form

$$
d_{t} \leq \theta y_{t+1}^{c} / R_{t}
$$

${ }^{5}$ Notice that only consumption goods are used as inputs in both the consumption and housing sectors (henceforth, $C$ sector and $H$ sector, respectively). 
where $y_{t+1}^{c}=A^{c} x_{t}$. In contrast to the assumption maintained for the $H$ sector, we introduce heterogeneity in the degree of pledgeability across investors' projects in the $C$ sector. Namely, the highest loan-to-value parameter $\theta$ in (4) is investor-specific. The reason to consider this heterogeneity is that, as it will be clear below, we want to obtain marginal movements of investors across sectors when the financial conditions in the economy change. In particular, we want to avoid to all investors in the $C$ sector jump out of this sector when there is a change, for instance, in the interest rate. Thus, we assume that $\theta$ is distributed across investors according to a well-behaved distribution function with support on the interval $[\underline{\theta}, \bar{\theta}]$ for $\{\underline{\theta}, \bar{\theta}\} \in(0,1)$ and with density function $f(\cdot)$.

As discussed in the Introduction, this paper is concerned with the macroeconomic effects of asymmetric financial conditions across sectors. In this sense, the evidence provided in Figure 1 suggests that firms in the housing (construction) sector may have better access to credit that those in the consumption (manufacturing) sector. We take this into the model by assuming that investment projects in the $H$ sector allow all investors to pledge a greater fraction of future output as collateral than an alternative project in the $C$ sector. More specifically, we consider that

Assumption 1: $\bar{\theta}<\theta^{h}$.

Young investors at $t$ pursue the investment alternative in which, after taking the optimal decisions, they can obtain the maximal rents at $t+1$. We denote by $\omega_{t+1}^{i}$ the investors net worth at the beginning of $t+1$. This depends on which project they undertook when young, $i=c, h, l$. An optimizing lender simply lends all his endowment in the first period of life. Thus, his net worth at the beginning of his second period of life is $\omega_{t+1}^{l}=R_{t}$. Instead, investors in the $C$ and $H$ sectors obtain $\omega_{t+1}^{c}=y_{t+1}^{c}-R_{t} d_{t}$ and $\omega_{t+1}^{h}=P_{t+1} y_{t+1}^{h}-R_{t} d_{t}$, respectively. ${ }^{6}$ We deal next with the optimal investment decisions within those sectors. Afterwards, we explain the old investors' utility maximization problem. We postpone the question of how agents optimally allocate across projects to section 3 .

\subsubsection{Optimal level of investment in $C$}

An investor in the $C$ sector seeks to maximize $\omega_{t+1}$ subject to the feasibility constraint (1), the flow of funds constraints (2) and the borrowing limit (4), taking as given the price of consumption goods and the technology of the sector. As our interest here is on interior equilibria in which the economy produces consumption goods (beyond the exogenous endowments), we need to assume that investment in the $C$ sector is always more profitable than lending:

\footnotetext{
${ }^{6}$ Notice that the second period net worth of an investor in the $C$ sector, $\omega_{t+1}^{c}$, depends on his pledgeability rate $\theta$. We make this dependence explicit below.
} 
Assumption 2: $A^{c}>R_{t}$.

Assumption 2, however, is not sufficient to ensure the existence of such interior equilibria since, in principle, the minimum size constraint may deter all investors from investing in the $C$ sector. On the other extreme, assumption 2, together with a CRS technology, imply that investors in this sector would ideally wish to undertake unboundedly large projects. To rule out both extremes, we impose the following assumption:

Assumption 3: $1<\frac{R_{t}}{\bar{\theta} A^{c}} \leq \frac{m}{m-1}$.

First, combining (2) and (4), we learn that $R_{t} / \bar{\theta} A^{c}>1$ ensures that the investor with the largest credit capacity, $\bar{\theta}$, can only borrow in a finite amount. Hence, the latter is true for all investors. Second, combining (2), (4) and (1), holding as equalities, we learn that $\frac{R_{t}}{\bar{\theta} A^{c}} \leq \frac{m}{m-1}$ implies that, at least, the latter investor can finance the minimum investment, $m$.

Given assumption 2, investors in this sector optimally put their total endowment as downpayment in a project with the maximum leverage so that the borrowing constraint (4) binds. Thus, the optimal volume of investment satisfies,

$$
x_{t}=\frac{R_{t}}{R_{t}-\theta A^{c}} .
$$

Hence, the size of the investment project $x_{t}$, is negatively related to the interest rate and positively related to the investor-specific rate of pledgeability, $\theta$.

\subsubsection{Optimal level of investment in $H$}

An investor in the $H$ sector maximizes $\omega_{t+1}$ subject to constraints (1), (2) and (3), taking as given the technology of the sector and the housing price. Regarding the latter, in equilibria where some new houses are produced at time $t$ (at least one investor of that generation invests in the $H$ sector), the following two conditions must hold,

$$
P_{t+1} A^{h} \geq R_{t}
$$

and

$$
1<\frac{R_{t}}{\theta^{h} P_{t+1} A^{h}} \leq \frac{m}{m-1}
$$

The inequality in (6) ensures that the return of a project in this sector is not lower than the interest rate. The sign conditions in (7) ensure, first, that the minimum investment constraint is not binding for a project with the maximum leverage and, second, that projects in this sector have a finite size. Thus, as regards their economic meaning, (6) and (7) resemble the content of assumptions 2 and 3, respectively. However, there is an important qualification. While 
assumptions 2 and 3 are conditions on parameters only, (6) and (7) involve the housing price, i.e. an endogenous variable. Thus, the latter are interior equilibrium conditions. ${ }^{7}$

Given those conditions, the optimal volume of investment for an investor in this sector is given by

$$
x_{t}=\left\{\begin{array}{lll}
\in\left[m, \frac{R_{t}}{R_{t}-\theta^{h} P_{t+1} A^{h}}\right], & \text { if } & P_{t+1} A^{h}=R_{t} \\
\frac{R_{t}}{R_{t}-\theta^{h} P_{t+1} A^{h}}, & \text { if } & P_{t+1} A^{h}>R_{t}
\end{array} .\right.
$$

The investment equation (8) differs from its $C$ sector counterpart (5) in one important respect. In principle, nothing precludes that $P_{t+1}$ is sufficiently low so that the investor is just indifferent between investing in the $H$ sector and lending his endowment, which happens when (6) holds as an equality. In such a case, the investor may not use all his credit capacity, so that (3) does not bind. Then, any level of investment lying between $m$ and the one consistent with (3) holding as an equality, i.e. $R_{t} /\left(R_{t}-\theta^{h} P_{t+1} A^{h}\right)$, yields the same net profit. This indeterminacy result is depicted in the top line of (8). If, on the contrary, $P_{t+1}>R_{t} / A^{h}$, then the cost of external funds falls strictly below the investment return so that it is optimal to invest (and borrow) as much as possible, in which case $x_{t}$ is given by the expression in the bottom line of $(8)$.

\subsubsection{Investors' utility maximization}

In the second period of life, investors collect the output of their projects, repay outstanding debts inclusive of interest and devote any remaining surplus to consume goods and housing services. At period $t+1$, an investor born at $t$ seeks to maximize the following objective function,

$$
U_{t}=\gamma \log h_{t+1}+\log c_{t+1}
$$

subject to the flow of funds constraint in that period

$$
c_{t+1}+Q_{t+1} h_{t+1} \leq \omega_{t+1}^{i}
$$

where, as defined above, $\omega_{t+1}^{i}$ is the investor's net worth at the beginning of his second period of life and it depends on which sector he invested when young, $i=c, h, l . c_{t+1}$ and $h_{t+1}$ represent consumption of goods and housing services, respectively, and $Q_{t+1}$ is the unit price of housing services. Housing services, as explained in detail below, are produced out of the existing housing stock and traded by a continuum of real estate intermediaries. The positive constant $\gamma$ captures

\footnotetext{
${ }^{7}$ Notice that out of the steady state it is possible to find equilibria with no production of new houses. That would be the case if the initial stock of housing is sufficiently high so that the price, even with no new production, is sufficiently low to drive the gross return from producing houses, $P_{t+1} A^{h}$, below the interest rate.
} 
the relative weight placed by the agent on housing services relative to consumption.

Notice that old investors spend, by virtue of the logarithmic form of preferences, a constant fraction $1 /(1+\gamma)$ of their net worth on goods and the remaining on housing services, regardless of the sector in which they invested when young. Thus, $c_{t+1}=\frac{1}{1+\gamma} \omega_{t+1}$ and $h_{t+1}=$ $\frac{\gamma}{1+\gamma} \omega_{t+1} / Q_{t+1}$.

\subsection{Consumers}

A measure $\pi$ of consumers is born every period and, like investors, they live for two periods. In each period of life, they are endowed with one unit of consumption goods. ${ }^{8}$ The only decision they take is how to spend their endowment, in each period, between consumption goods and housing services in order to maximize utility. Namely, a consumer born at period $t$ maximizes, both when young $(i=t)$ and when old $(i=t+1)$, the following objective function,

$$
U_{i}=\gamma \log h_{i}+\log c_{i}
$$

subject to the budget constraint

$$
c_{i}+Q_{i} h_{i} \leq 1
$$

Consumers in this economy behave in a really trivial way and all the qualitative results obtained in this paper are robust to the omission of these agents from the model. They are useful, however, for the quantitative analysis develop in section 4.

\subsection{Housing intermediaries}

A measure 1 of housing intermediaries, who also live for two periods, is born in every period. Intermediaries use the housing stock to produce the period by period flow of housing services, which is assumed to be identical to the stock. ${ }^{9}$ Housing services are then sold in a competitive market to consumers and old investors at a unit price $Q_{t} \cdot{ }^{10}$ An intermediary born at $t$ maximizes the profit function

$$
\Pi_{t+1}^{h}=(1-\delta) P_{t+1} h_{t}^{h}-R_{t} d_{t}^{h},
$$

\footnotetext{
${ }^{8}$ Investors only receive endowment in their first period of life. Considering instead that, like consumers, investors receive endowment both when young and old would not have any relevant effect on the predictions of the model.

${ }^{9}$ The stock of houses in the economy, $H_{t}^{s}$, evolves according to the law of motion $H_{t}^{s}=(1-\delta) H_{t-1}^{s}+Y_{t}^{h}$, where $\delta$ is the rate of depreciation of the housing stock and $Y_{t}^{h}$ is the aggregate production of new houses.

${ }^{10}$ Housing intermediaries can be seen as landlords that rent out their housing stock to consumers and old investors at a rental price $Q_{t}$. Under this view, the existence of a rental market in this economy allows us to treat separately the investment and consumption decisions that every investor faces when young and old, respectively. Absent such rental market, young investors would face a more complex problem in which they would choose the optimal allocation of their endowment between house purchases and productive investments. This is the reason why we introduce the sector of housing intermediaries.
} 
subject to the flow of funds constraint

$$
\left(P_{t}-Q_{t}\right) h_{t}^{h}=d_{t}^{h}
$$

where $h_{t}^{h}$ and $d_{t}^{h}$ represent the housing stock hold by the intermediary and the volume of borrowed funds, respectively. Expression (14) contains the timing assumption that an intermediary purchases houses at time $t$, which are used to produce housing services during the same period. We do not impose any collateral constraint on debt holdings by intermediaries and we assume that they have zero initial endowment. Profits are then defined in (13) as the difference between the market value of the non-depreciated fraction of the housing holdings and debt repayments, inclusive of interest. Competition among intermediaries leads profits to zero. In particular, it happens that

$$
Q_{t}+(1-\delta) \frac{P_{t+1}}{R_{t}}=P_{t}
$$

This last expression is intuitive. It states that the marginal revenue from an extra housing unit, which corresponds to the price of the extra unit of housing services, $Q_{t}$, plus its discounted resale value, net of depreciation, $(1-\delta) P_{t+1} / R_{t}$, must be equal to the cost of such extra unit, $P_{t}$. Thus, intermediaries are indifferent regarding how much housing stock to hold and this decision is fully determined by the aggregate demand of housing services.

\section{Steady state analysis}

In this section we explore the steady state properties of the model. Specifically, we focus on interior stationary equilibria in which some tradeable goods are produced. ${ }^{11}$ Since any steady state in this economy must involve an active $H$ sector, the equilibrium house price must satisfy the steady state versions of both (6) and (7). Thus,

$$
P \geq \max \left\{\frac{R}{A^{h}}, \frac{m-1}{m} \frac{R}{\theta^{h} A^{h}}\right\} .
$$

This condition says that $P$ must be sufficiently high so that, first, investment in that sector is, at least, as much profitable as lending and, second, the value of a project in the housing sector generates enough collateral to overcome the minimum scale constraint (1). For the sake of generality, we assume that $1-1 / m<\theta^{h}$. This implies that $\frac{R}{A^{h}}>\frac{m-1}{m} \frac{R}{\theta^{h} A^{h}}$ so that the relevant lower bound for the steady state housing price is $P \geq \frac{R}{A^{h}} \cdot{ }^{12}$

\footnotetext{
${ }^{11}$ In steady state the economy must produce some houses since they are non-tradeable goods subject to depreciation and the utility function of investors and consumers satisfies $\lim _{H \rightarrow 0} U \rightarrow \infty$. However, we can not invoke a symmetric argument for tradeable goods, since the presence of an exogenous endowment of these goods allows for the possibility of zero (endogenous) production.

${ }^{12}$ This assumption goes in favor of generality since it implies that there may exist steady state equilibria with non-binding borrowing limits in the housing sector, as those analyzed below.
} 


\subsection{Endogenous investors segmentation}

In analyzing how investors optimally allocate across sectors, it is useful to distinguish between steady state equilibria where $P=\frac{R}{A^{h}}$ and steady state equilibria where $P>\frac{R}{A^{h}}$. We next deal with these two types of interior equilibria. Afterwards, in section 3.2 we discuss which type of equilibria is more likely depending on the interest rate.

\subsubsection{An unconstrained housing sector}

Consider a situation in which the unit return in the $H$ sector equals the interest rate, i.e. $P A^{h}=R$. In such a case, the borrowing constraint (3) does not bind and any investor in the $H$ sector is indifferent between engaging in that investment and lending his endowment in the international capital market. As a result, the aggregate supply of houses is completely elastic and the equilibrium volume of production is determined by the demand.

In the absence of rents above the interest rate in the $H$ sector, positive rents in the $C$ sector, $A^{c}-R>0$, imply that it is optimal to invest on it for everyone who find it feasible, i.e. for everyone whose $\theta$ is sufficiently high so that his project satisfies (1). We denote by $\theta^{F}$, for feasibility, the lowest $\theta$ such that the feasibility constraint (1) is satisfied. Combining (1), holding as an equality, with (5) we find that

$$
\theta^{F}=\frac{m-1}{m} \frac{R}{A^{c}}
$$

The above expression is intuitive. A higher minimum scale $m$, requires more credit to carry on the project and this leads to a higher $\theta^{F}$. A higher interest rate, that reduces the collateral value of the project, also causes $\theta^{F}$ to increase. Likewise, a low value of the project, as captured by a low $A^{c}$, goes hand in hand with a higher $\theta^{F}$, since then the project, given everything else, produces less collateral.

Therefore, investors with pledgeability rates $\theta \geq \theta^{F}$ invest in the $C$ sector. Hereinafter, we denote by $\theta^{*}$ the pledgeability rate of the marginal investor, that with the lowest $\theta$ among those investing in the $C$ sector. In this case, $\theta^{*}=\theta^{F}$. Investors with $\theta<\theta^{F}$ are indifferent between investing in $H$ and lending his endowment. As stated above, their decision is driven by the demand of housing.

Using the steady state counterpart of the non-arbitrage condition (15), and aggregating the demand for housing services across old investors and young and old consumers, we can write 
the aggregate demand for houses (equivalently, housing services), denoted by $H^{d}$, as

$$
H^{d}=\frac{\gamma}{1+\gamma} \frac{A^{h}}{R-1+\delta}\left\{2 \pi+R+\int_{\theta^{*}}^{\bar{\theta}} \frac{A^{c}-R}{1-\theta A^{c} / R} f(\theta) d \theta\right\}
$$

The term in brackets in the right hand side of (18) is the total income of those agents. $2 \pi$ is just the endowment of young and old consumers. Investors in the $H$ sector and lenders all have a net worth equal to $R$. Investors in the $C$ sector, instead, obtain $R$ plus an excess return. The latter is just the unit excess return, or unit rents, $A^{c}-R>0$, times the size of the investment project with the highest leverage, $1 /\left(1-\theta A^{c} / R\right)$. Some simple algebra shows that $\frac{d H^{d}}{d R}<0$, which is the result of two reinforcing effects. First, given that housing is a durable good, a fall in $R$ implies an outward shift in the demand schedule since the user cost of housing falls. The latter substitution effect more than compensates the negative wealth effect suffered by lenders. Second, a lower $R$ increases the rents of investors in $C$ and also allow more investors to invest in the $C$ sector (i.e. $\theta^{*}$ goes down), hence raising total rents in the economy which further fuels the demand for housing.

\subsubsection{A constrained housing sector}

In equilibria in which $P A^{h}>R$, both investors in the $H$ and $C$ sectors obtain rents (above the interest rate) and the borrowing constraint in the $H$ sector is binding. Importantly, rents per unit invested in the $H$ sector, while positive, must be lower than in the $C$ sector, i.e. $P A^{h}<A^{c}$. To see this, notice that equal unit rents in both sectors, $P A^{h}=A^{c}$, together with a higher degree of pledgeability for housing investments (assumption 1) would imply that total rents would be strictly greater in the $H$ sector than in the consumption one for every investor. Hence, a positive pledgeability premium, defined as $A^{c}-P A^{h}$, is a necessary condition for the existence of an interior equilibrium.

As opposed to the equilibria characterized in the previous section, positive rents in the $H$ sector open the possibility that some investors optimally choose this sector even if they are able to run a project in the $C$ sector, i.e. they can afford an investment that satisfies the minimum size requirement in that sector. Intuitively, since investors decide in which sector to invest based on total rents, the optimal choice ultimately takes into consideration both unit rents and the size of the project. In this sense, whereas a positive pledgeability premium ensures that unit rents are higher in the $C$ sector, higher pledgeability of projects in housing allow for larger projects. Thus, under some conditions, investors with lower pledgeability rates $\theta$, may find optimal to sacrifice higher unit rents in the $C$ sector and run larger projects with lower unit rents in the $H$ sector. Such trade-off lies at the heart of the central mechanism of this paper. 
As before, let us denote by $\theta^{*}$ the pledgeability rate of the marginal investor, that with the lowest $\theta$ among those investing in the $C$ sector. For such an investor the following condition holds,

$$
\omega^{c}\left(\theta^{*}\right) \geq \omega^{h}
$$

(Herein, we emphasize the dependence of the second period net worth after investing in the $C$ sector, $\omega^{c}\left(\theta^{*}\right)$, on the investor specific rate $\theta$. In contrast, net worth after investing in the $H$ sector, $\omega^{h}$, is the same for all investors.) Since total rents in the $C$ sector are increasing in the individual rate $\theta$, it follows that all investors with $\theta>\theta^{*}$ invest in the $C$ sector while the rest choose the housing one.

In order to characterize $\theta^{*}$ further it is useful to distinguish two cases, depending on whether (19) holds as an equality or not. First, imagine that rents obtained by the marginal investor in the $C$ sector lie strictly above the ones that he would get in the $H$ sector. In that case, we learn that $\theta^{*}$ is such that the marginal investor meets exactly the minimum investment requirement and, hence, $\theta^{*}=\theta^{F}$, as in the unconstrained $H$ sector studied before.

Second, imagine that the marginal investor is able to finance the minimum investment in both sectors and, hence, he would obtain the same total rents in both sectors. ${ }^{13}$ In this latter case, $\theta^{*}=\theta^{P}$, where $\theta^{P}$, for profitability, is implicitly defined by the following equality,

$$
\frac{A^{c}-R}{R-\theta^{P} A^{c}}=\frac{P A^{h}-R}{R-\theta^{h} P A^{h}} .
$$

This last expression makes clear that, given a positive pledgeability premium, the marginal investor is indifferent between both sectors iff investment with maximum leverage in the $H$ sector is larger than the corresponding investment in the $C$ sector, i.e.

$$
\theta^{h} P A^{h}>\theta^{P} A^{c}
$$

Further, as the minimum investment requirement must be satisfied in any event, we learn that (20) meaningfully characterizes the marginal investor iff $\theta^{P} \geq \theta^{F}$. Thus, putting things together, the marginal investor is identified by

$$
\theta^{*}=\max \left\{\theta^{F}, \theta^{P}\right\}
$$

This last expression plays a central role in the analysis that follows. As our main interest here is in analyzing how changes in the interest rate affect investment, credit and output composition, we next study the effects of $R$ on $\theta^{*}$ which, in view of (22), is tantamount to understanding how $\theta^{F}$ and $\theta^{P}$ respond to changes in $R$.

\footnotetext{
${ }^{13}$ The equality of total rents in both sectors for the marginal investor follows from the fact that the distribution of $\theta$ is continuous.
} 
As regards $\theta^{F}$, we learn from (17) that $\frac{d \theta^{F}}{d R}>0$. A higher interest rate reduces the net present value of projects in the $C$ sector which, in turn, reduces the amount of external funding available. This, given limited internal funds, makes that fewer investors can reach the minimum investment size in $C$ (i.e., $\theta^{F}$ increases).

Things are slightly more complicated with $\theta^{P}$. The partial effect of $R$ on $\theta^{P}$ is negative, i.e. $\frac{\partial \theta^{P}}{\partial R}<0$. This is intuitive. Consider, for instance, that $R$ falls. We learn, combining (21), (5) and (8), that, given $P$, the size of the project that the investor with pledgeability rate $\theta^{P}$ may run in the $H$ sector increases more than the size of the project that he could run in the $C$ sector. Given that this investor was indifferent between sectors before the change in $R$, he must now prefer the housing sector. Thus, $\theta^{P}$ increases. However, we must take into account that $R$ also affects $P$. In principle, the effect of $R$ on $P$ is uncertain since both the housing demand and supply schedules shift outwards as $R$ falls. ${ }^{14}$ In what follows we restrict our attention to the more natural case in which the demand response overwhelms that of the supply and, therefore, $\frac{d P}{d R}<0 .{ }^{15}$ The fact that $P$ increases following a fall in $R$ reinforces the partial effect of $R$ on $\theta^{P}$ discussed above and therefore makes that $\frac{d \theta^{P}}{d R}<0 .{ }^{16}$

\subsection{The effect of interest rates on the steady state}

We now analyze how the steady state equilibrium of this economy depends on the interest rate. We restrict to the interval $(\underline{R}, \bar{R})$. The upper bound $\bar{R}$ is defined as the highest interest rate for which an interior stationary equilibrium exists, in the sense that for any $R>\bar{R}$ the investor with highest pledgeability $\bar{\theta}$, can not afford the minimum investment size in $C$. Thus, $\bar{R}$ is the interest rate that satisfies (1) as an equality in the $C$ sector for the investor with pledgeability $\bar{\theta}$. The lower bound $\underline{R}$ is defined as the lowest rate for which that investor, i.e. the one who obtains the highest rents in the $C$ sector, is indifferent between both sectors. Hence, $\underline{R}$ is the rate that satisfies (20) when $\theta^{P}=\bar{\theta}$. We consider three interest rate regions: 1) $R \in\left(R^{*}, \bar{R}\right)$, 2) $R \in\left(R^{* *}, R^{*}\right)$, and 3) $R \in\left(\underline{R}, R^{* *}\right)$, where $R^{*}$ and $R^{* *}$ are defined below.

In the first region, $R$ is sufficiently high so that few investors can afford the minimum investment requirement in the $C$ sector. As a result, there is a large amount of resources

\footnotetext{
${ }^{14}$ The outwards shift in demand is straightforward and it has been partly discussed before. As for the supply of housing, both the intensive investment margin (i.e. the size of the project for each investor) and the extensive margin (i.e. the number of investors), as just shown, respond positively to a fall in $R$.

${ }^{15}$ Of course, such sign condition can only be guaranteed if the parameters of the model satisfy some boundary conditions. For instance, it becomes clear that for sufficiently high $\pi$, which affects the measure of individuals demanding houses relative to those producing them, the impact of $R$ on the demand curve will dominate the eventual shift of the supply curve.

${ }^{16} \frac{d P}{d R}<0$ is just a sufficient condition to obtain $\frac{d \theta^{P}}{d R}<0$. The necessary condition that guarantees $\frac{d \theta^{P}}{d R}<0$ is that $\frac{d P}{d R}<\varphi$, where $\varphi>0$ and depends on the parameters of the model. This will be clear in the quantitative exercises below, where $\frac{d \theta^{P}}{d R}$ is always $<0$ while the relation between $P$ and $R$ is sometimes positive.
} 
available for investment in housing while, at the same time, high $R$ implies that the demand for housing services is low. Both low demand and a large number of potential investors in housing imply that rents in this sector are zero (i.e. unconstrained housing sector type equilibrium). Thus, in this region $\theta^{*}=\theta^{F}$ and a fall in $R$ allows some investors to jump into the $C$ sector to begin to obtain positive rents. In this way, within this region, lower interest rates allow for an increasing number investors to move into the more productive sector.

As discussed above, lower interest rates also raise the aggregate demand for housing. As a consequence, the demand for funds of investors in the $H$ sector raises and/or the number of lenders decreases (recall that in this region lenders and investors in $H$ obtain the same rents), for these are the two channels through which the economy may end up producing more houses. That is, a lower $R$ triggers an expansion in the intensive margin of the supply, which tends to push credit capacity of housing producers towards its limit, or in the extensive margin or both. Taking the previous argument a step further, it becomes intuitive that for a sufficiently low $R$ both the extensive and intensive margins of the housing supply reach their respective limits. ${ }^{17}$ That is, the scenario is such that, simultaneously, no agent with an opportunity to invest chooses to lend and all investors in $H$ exhaust their credit capacity. Such a limiting rate, denoted by $R^{*}$, is the rate for which the following two conditions simultaneously hold: (i) $P A^{h}=R$ and (ii) the borrowing constraint (3) holds as an equality for housing producers. Formally, $R^{*}$ is the unique solution to the following market clearing condition,

$$
H^{d}=\frac{1}{\delta} \int_{\underline{\theta}}^{\theta^{*}} \frac{A^{h}}{1-\theta^{h}} f(\theta) d \theta
$$

where the exact expression for the aggregate demand for housing services or, equivalently, for houses, is given by (18). The right hand side of (23) captures the total stock of houses in the economy when the two conditions above are met. Uniqueness of $R^{*}$ follows from the fact that $H^{d}$ is a monotonic decreasing function of $R$ whereas $\theta^{*}$, according to (17), is a monotonic increasing function of $R$.

In the second region, once $R$ falls below $R^{*}$, positive rents (above interest rates) in the $H$ sector are needed so that the housing supply is able to meet the increased housing demand (i.e. constrained housing sector type equilibrium). ${ }^{18}$ However, interest rates are still relatively high. Thus, both projects in the $H$ and $C$ sectors are still relatively small and, in terms of the trade-off faced by investors, the differences in unit rents across sectors dominate the differences in project sizes. Hence, the $C$ sector is more attractive to investors and every investor who

\footnotetext{
${ }^{17}$ Recall that, since the number of investors in the $C$ sector increases following a fall in $R$, a rise in the extensive margin of the housing supply is limited to a contraction in the measure of existing lenders.

${ }^{18}$ Thus, there are unconstrained housing sector type equilibria for $R \geq R^{*}$ and constrained housing sector type equilibria for $R<R^{*}$.
} 
can satisfy the minimum size requirement in the $C$ sector optimally decide to invest there. Intuitively, the equilibrium allocation of investors across sectors within this region is driven by feasibility. Namely, $\theta^{*}=\theta^{F}>\theta^{P}$. As in Region 1, a fall in interest rates within this region induces a reallocation of investors towards the more productive sector, $C$.

In the third region, as $R$ reaches sufficiently low values, projects gets larger but most investors can run, due to the better financial conditions in the $H$ sector, much more larger projects in the $H$ sector than in the $C$ sector. At this time, differences in project sizes across sectors dominate the differences in unit rents (pledgeability premium) and some investors for whom it is feasible to invest in the $C$ sector prefer to invest in the $H$ sector where, despite of lower unit rents, they can obtain larger total rents by having much larger projects. Thus, intuitively, the equilibrium allocation of investors across sectors within this region is not driven by feasibility but by profitability. More specifically, in this region $\theta^{*}=\theta^{P}>\theta^{F}{ }^{19}$ Notice also that, as opposed to regions 1 and 2, a fall in interest rates in this region reallocates investors towards the least productive (in terms of unit rents) sector, $H$.

Summing up, Figure 3 plots $\theta^{P}, \theta^{F}$ and $\theta^{*}$ as functions of $R$ over the interval $(\underline{R}, \bar{R}) .{ }^{20}$ The figure makes clear that there is a hump-shaped relationship between interest rates and the mass of investors who optimally decide to invest in the $C$ sector (dotted area). When interest rates are high (regions 1 and 2) a fall in $R$ mostly alleviates the investors' feasibility constraint and they move towards the more productive sector, $C .{ }^{21}$ Instead, when interest rates are low (Region 3), a fall in $R$ emphasizes the better financial conditions in the $H$ sector and investors tend to leave the $C$ sector towards the $H$ sector where they can run much larger projects. In section 4 , we study further the macroeconomic impact that this sectoral reallocation of investors, induced by changes in the interest rates, has on the economy. Before that, in the following section, we discuss how the results would change in a model where financial conditions in the economy are the same across sectors and investors.

\footnotetext{
${ }^{19}$ Notice that, while for interest rates sufficiently close (from the left) to $\bar{R}$ it must necesarily be the case that $\theta^{*}=\theta^{F}$, when $R=\underline{R}$ it happens that $\theta^{*}=\theta^{P}$. Then, given that both $\theta^{P}$ and $\theta^{F}$ are monotonic functions of $R$ (as discussed above, $\frac{d \theta^{F}}{d R}>0$ and $\frac{d \theta^{P}}{d R}<0$ ), there must exists a rate $R^{* *}$ within the range $(\underline{R}, \bar{R})$ for which $\theta^{*}=\theta^{F}=\theta^{P}$.

${ }^{20}$ The analysis developed in this section refers to the more general case where the three interest rate regions defined above exist. But of course, depending on the parameters of the model, it could well be the case that, for instance, Region 1 does not exist. This is just a particular case of the model that happens when $R^{*}>\bar{R}$.

${ }^{21}$ The relevance of the assumption of a minimum size requirement for investment in the $C$ and $H$ sector becomes evident here. Absent that minimum size requirement there would not be regions 1 and 2, and the economy would always be within Region 3. In section 4, we further illustrate the importance of $m$ in determining the type of equilibrium the economy is in.
} 


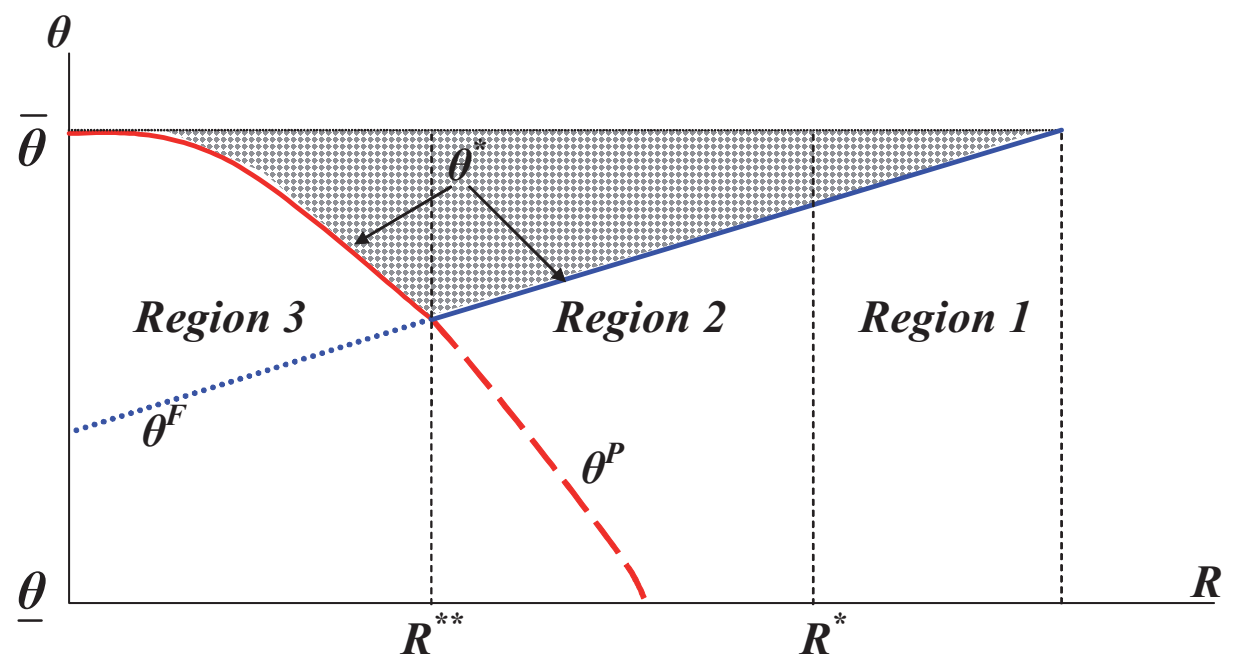

Figure 3. Investors' endogenous segmentation.

\subsection{A benchmark case with symmetric pledgeability}

The analysis presented so far has focused on our central case in which the economy features asymmetric collateral requirements across projects, as stated in assumption 1 . We now describe the special case in which the collateral requirements are symmetric across projects and investors in the economy. Namely, we consider that the pledgeability rate in the $C$ sector is common to all investors and equal to $\theta^{h}$, the pledgeability rate in the $H$ sector. This case provides a useful benchmark against which we analyze the role of asymmetries in credit conditions presented above.

A first consequence of symmetric pledgeability rates is that, in an interior steady state equilibrium, the unit return in both sectors, $C$ and $H$, must be the same. That is, the pledgeability premium is zero and $P=A^{c} / A^{h}$. Projects in $C$ and $H$ now have the same optimal size and investors obtain the same total rents in both sectors (i.e., there is no trade-off whatsoever). This further implies that the equilibrium production of housing is demand determined, much as in the case studied in section 3.1.1. The housing market clearing condition is now

$$
\frac{\phi^{h}}{\delta} \frac{1}{1-\theta^{h} A^{c} / R}=\frac{\gamma}{1+\gamma} \frac{R / A^{c}}{R-1+\delta}\left\{2 \pi+\frac{1-\theta^{h}}{1-\theta^{h} A^{c} / R} A^{c}\right\}
$$

where $\phi^{h}$ is the measure of investors in the $H$ sector and the left and right hand sides of the equation correspond to the total housing supply and demand, respectively. This equation determines a unique equilibrium value of $\phi^{h}$. 
As regards the effects of changes in the interest rate on $\phi^{h}$, it is easily verified that

$$
\operatorname{sign}\left\{\frac{d \phi^{h}}{d R}\right\}=\operatorname{sign}\left\{(1-\delta)\left(\theta^{h}-1-\frac{2 \pi}{A^{c}}\right)+2 \pi \theta^{h}\right\}
$$

Therefore, the impact of $R$ on the extensive margin, $\phi^{h}$, is monotonic and it depends on the parameters of the model. Thus, the hump-shaped relationship between interest rates and the extensive margin obtained in the model with financial asymmetries across sectors does not extend to this symmetric case. More importantly, notice that, in this symmetric case, the monotonic relation between $R$ and $\phi^{h}$ translates into a similar monotonic relation between $R$ and the ratio of aggregate investment across sectors. In this sense, simply note that, in this benchmark case,

$$
\frac{X^{c}}{X^{h}}=\frac{1-\phi^{h}}{\phi^{h}}
$$

where $X^{c}$ and $X^{h}$ denote aggregate investment in the $C$ and $H$ sectors, respectively. The fact that in this economy with symmetric collateral requirements the ratio $\frac{X^{c}}{X^{h}}$ always responds to changes in $R$ moving in the same direction, does not help in explaining the empirical humpshaped relationships depicted in Figure 2 and it highlights the relevance of taking financial asymmetries across sectors into account.

\section{Macroeconomic impact of investors' sectoral reallocation and comparative statics}

Sections 3 showed how investors optimally allocate across sectors in an economy with asymmetric financial conditions and how this endogenous segmentation depends on the interest rate. The objective of this section is to provide a deeper understanding, through calibration exercises, of the impact that changes in interest rates have on investors' segmentation, on prices and on the allocation of aggregate investment across sectors in this economy. It also analyzes the impact that key parameters of the model have on the type of equilibrium (region) the economy is in, on the pledgeability premium and on the share of investors in the $C$ sector. We illustrate these effects considering that $\theta$ is distributed according to a uniform distribution, and that the parameters of the model take the values in Table 1.

\begin{tabular}{ccccccccc}
\hline \hline \multicolumn{10}{c}{ Table 1. Baseline calibration } \\
\hline$\delta$ & $\gamma$ & $\pi$ & $m$ & $\theta^{h}$ & $\bar{\theta}$ & $\underline{\theta}$ & $A^{c}$ & $A^{h}$ \\
0.020 & 0.25 & 50 & 4 & 0.8 & 0.8 & 0.6 & 1.2 & 1.2 \\
\hline \hline
\end{tabular}


There is information in the literature on reasonable values for $\delta$ and $\gamma$. In line with this literature, we consider that housing depreciates a rate of $2 \%$ per annum and that $\gamma=0.25$, which imply that consumers' expenditure share on housing equals $20 \% .{ }^{22}$ Unfortunately, there are not as clear counterparts in the literature for the other parameters. Thus, besides using the values in the table above as benchmark estimates, we also show below how the results change when one deviates from these values. Note that $m=4$ implies that, in any project, external funds represent at least $75 \%$ of total investment, and that $\pi=50$ imposes that there is 1 investor per 50 consumers.

\subsection{Results for the baseline calibration}

Figures 4 and 5 reproduce, for this baseline calibration of the model, the analytical results presented in section 3.2 regarding investors' endogenous segmentation. As stated there, there is a non-monotonic relation between the extensive margin (how investors split between sectors) and interest rates. For high interest rates a decrease in $R$ is associated to a flow of investors towards $C$, while the opposite is true once interest rates fall below $R^{* *}$ (Region 3).

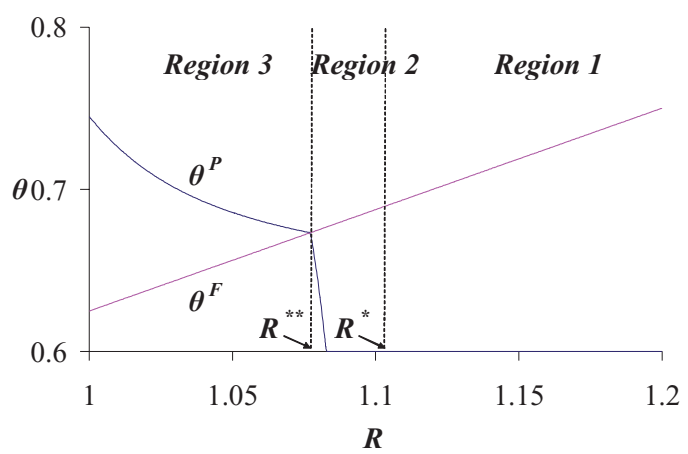

Figure 4. Threshold values in $\theta$.

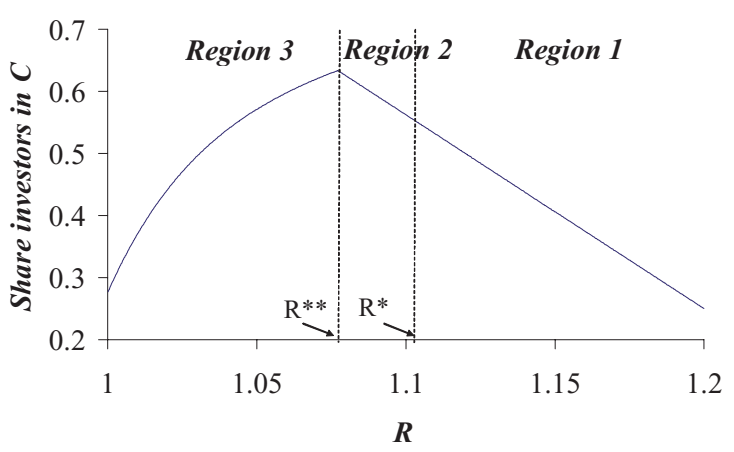

Figure 5. Share of investors in $C$.

Figure 6 shows how the ratio of aggregate investment across sectors, $\frac{X^{c}}{X^{h}}$, responds to interest rates for our baseline calibration. In principle, the behavior of this ratio in all three regions can be ambiguous. ${ }^{23}$ In this calibration, we find that movements in the extensive margin dominate those in the intensive margin, so the hump-shaped relationship of Figure 5 between investors' endogenous segmentation and interest rates translate into an analogous hump-shaped

\footnotetext{
${ }^{22}$ See, for instance, Van Nieuwerburgh and Weill (2006) and Davis and Ortalo-Magne (2007) regarding housing depreciation rates and consumers' expenditure shares on housing, respectively.

${ }^{23}$ In Region 3, as interest rates fall, $X^{h}$ unambiguously increases while $X^{c}$ decreases in the extensive margin but increases in the intensive margin. In Region 2, as interest rates fall, $X^{c}$ unambiguously increases while $X^{h}$ decreases in the extensive margin but increases in the intensive margin (note that $\frac{\partial\left(\frac{P}{R}\right)}{R}<0$ ). In Region 1, both $X^{c}$ and $X^{h}$ unambiguously increase as interest rates fall.
} 
relationship for $\frac{X^{c}}{X^{h}}$.

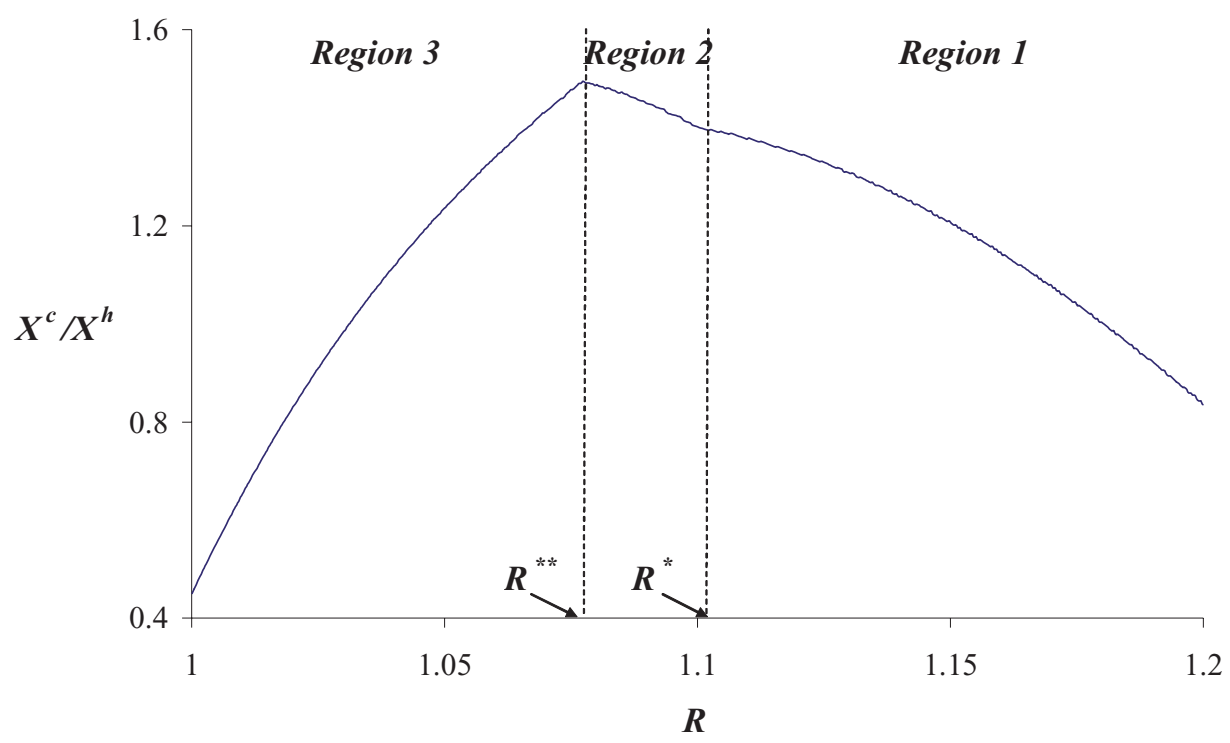

Figure 6. Ratio of aggregate investment across sectors.

This result can help to understand the same hump-shaped relationship observed in the data for many countries already discussed in the Introduction (Figure 2). In situations in which there is an asymmetric access to credit, the allocation of investment across sectors does not need to be monotonic. But also note that the compositional changes in aggregate investment reported in Figure 6 have a direct impact on the economy's aggregate TFP. In fact, the measure of aggregate TFP at constant prices in this economy behaves, with respect to interest rates, in exactly the same fashion as the ratio $\frac{X^{c}}{X^{h}} \cdot{ }^{24}$ In this sense, the model emphasizes the impact of sectoral reallocation on TFP, and it could be helpful to understand low productivity growth in countries where sectoral reallocation towards the housing sector has been intense, as it has been the case, for example, in Spain for the last few years.

Figure 7 shows how the relative price of housing responds to interest rates for our baseline calibration. As discussed in section 3, within Region 1 lending and investing in the $H$ sector have the same return and $P=\frac{R}{A^{h}}$. Therefore, a fall in the interest rate in this region leads to a fall in the relative price of housing. In regions 2 and 3 , the relationship between $P$ and $R$ depends on how housing demand responds to $R$ relative to housing supply. For our baseline calibration we find that, within Region 2 , there is a negative relationship between $P$ and $R$ while, within Region 3, the response of $P$ to interest rate falls is non-monotonic.

\footnotetext{
${ }^{24}$ At constant prices, $T F P=P_{0} A^{h}\left(\frac{X^{h}}{X^{h}+X^{c}}\right)+A^{c}\left(\frac{X^{c}}{X^{h}+X^{c}}\right)$
} 


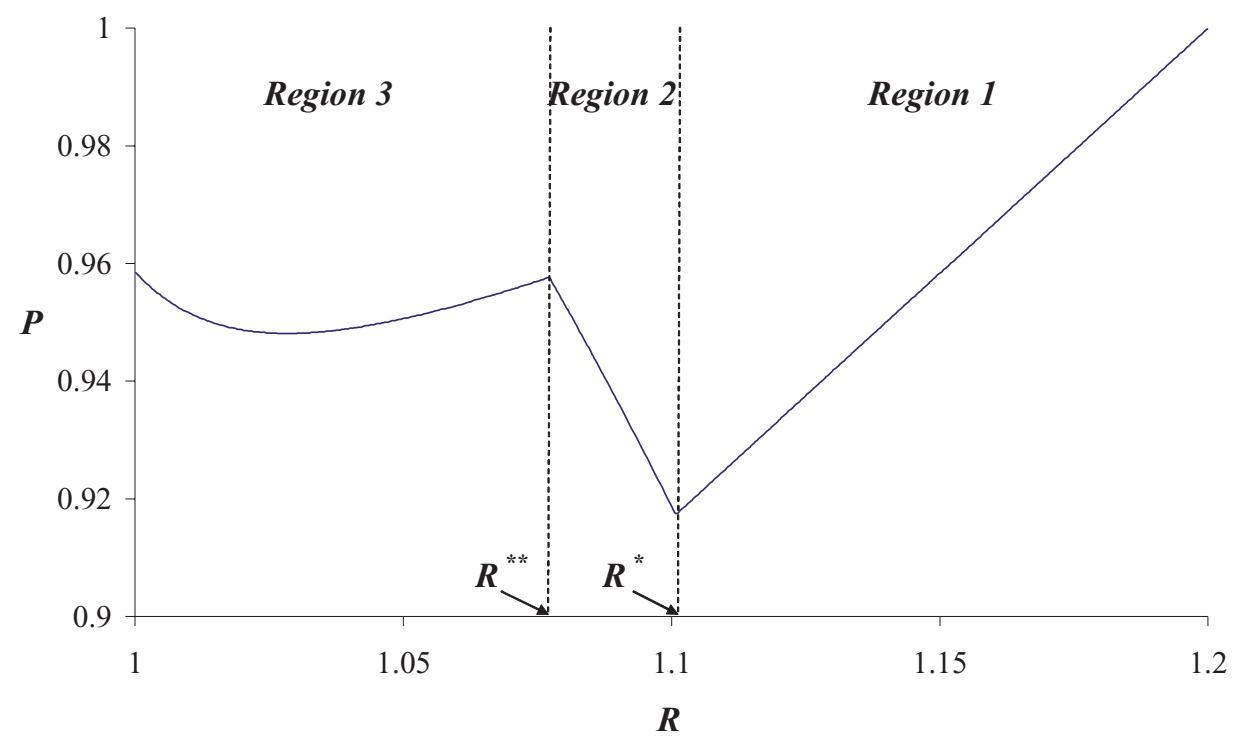

Figure 7. Relative price of housing.

Notice that we could have imposed restrictions on the parameters of the model to obtain a monotonic relation between $P$ and $R$ outside Region 1 . It is not the main purpose of this paper to explain the behavior of the relative price of housing (just note that our demand for housing is very stylized), so that we chose not to impose such restrictions for the sake of generality. Furthermore, note that for this baseline calibration we have that $\frac{d \theta^{P}}{d R}<0$ always outside Region 1 even though $\frac{d P}{d R}<0$ sometimes within Region 3. As discussed in section 3, $\frac{d P}{d R}<0$ is a condition stronger than needed to guarantee $\frac{d \theta^{P}}{d R}<0$.

Finally, Figure 8 shows what happens to this economy's external borrowing as a percentage of GDP when interest rates fall. Despite the fact that this model is too stylized to produce sensible magnitudes, we must highlight the fact that external borrowing in this economy behaves in a highly non-linear fashion. In a way, this is not surprising given the shape of our borrowing constraints. But note that this effect is reinforced in our model by the sectoral reallocation induced by interest rate falls. In particular, note that the slope in Figure 8 gets significantly steeper once the economy enters into Region 3, where investors tend to leave the $C$ sector towards the $H$ sector in which, ceteris paribus, access to financing is better. This feature of the model could be helpful to understand the sharp increases in current account deficits observed, for instance, in the U.S. and Spain in recent years where interest rates were very low and there were large shifts in production towards the housing sector. 


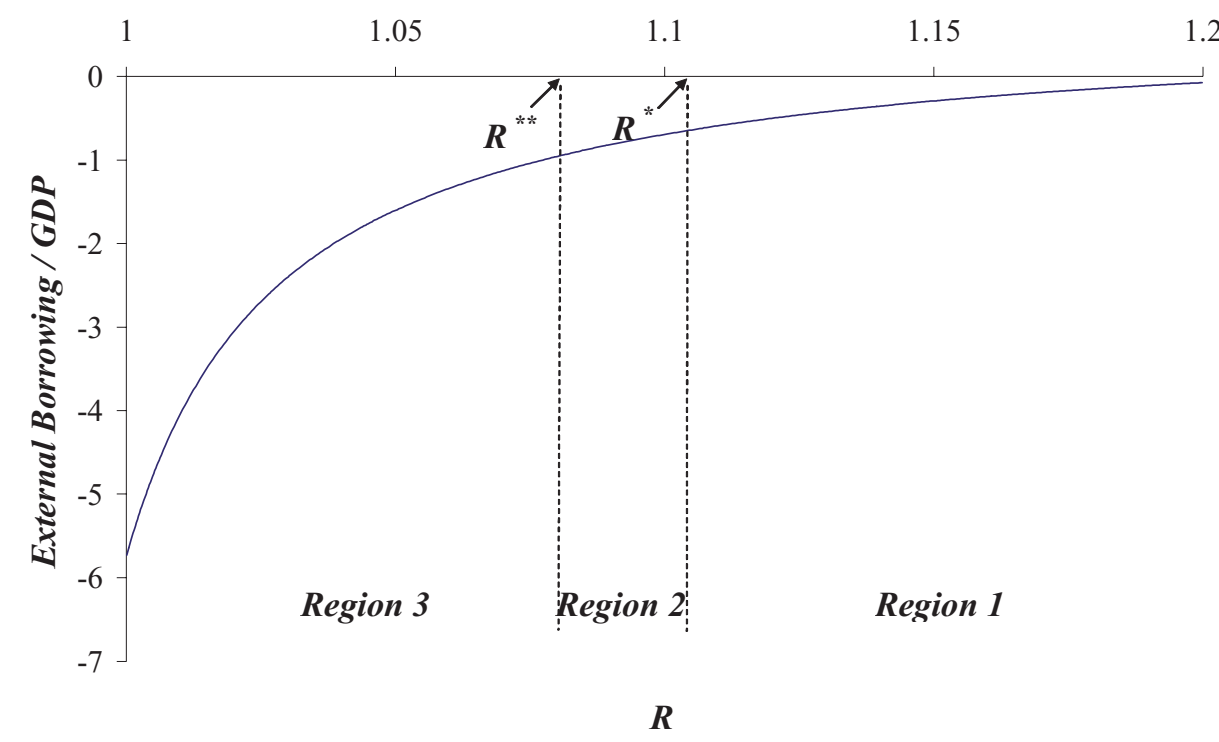

Figure 8. External borrowing over GDP.

\subsection{Comparative statics}

We now depart slightly from the baseline calibration presented above to see how some key parameters of model affect the type of equilibrium (region) the economy is in, the pledgeability premium and the share of investors in the $C$ sector. We focus on four parameters: the minimum investment size $(m)$, the pledgeability parameter in the housing sector $\left(\theta^{h}\right)$, the TFP level in the $C$ sector $\left(A^{c}\right)$ and the mass of consumers relative to investors in the economy $(\pi) .{ }^{25}$ In each of the exercises reported below we move one of these parameters at a time, while keeping all the rest at their values in the baseline calibration. Furthermore, unless otherwise noted, the exercises are performed considering $R=1.10$.

Figures 9 and 10 show what happens to the share of investors in the $C$ sector and to the pledgeability premium, respectively, when $m$ takes different values on the interval $[2,5] .{ }^{26}$ Increasing $m$ makes the feasibility constraint tougher and, for a given interest rate, it makes more likely that the investors' equilibrium allocation across sectors is driven by feasibility rather than by profitability. In other words, the larger $m$ the more likely that the economy's equilibrium

\footnotetext{
${ }^{25}$ Moving $A^{h}$ only produces a scale effect on $P$. To see this, just note that we can write all the relevant equations of the model in terms of $P A^{h}$, without isolated $P^{\prime} s$ or $A^{h \prime} s$. Thus, in equilibrium we really determine $\tilde{P}=P A^{h}$. This is also the reason why the exact value of $A^{h}$ in the calibration exercises does not mind for our purposes. Regarding $\bar{\theta}$ and $\underline{\theta}$, we prefer to illustrate the effects of increasing the financial asymmetry across sectors moving $\theta^{h}$ rather than any of those parameters. The underlying reason is that moving $\bar{\theta}$ or $\underline{\theta}$, not only affects the financial asymmetry across sectors, but it also modifies the pledgeability distribution $F(\theta)$, what distorts the exercises.

${ }^{26} m=2$ implies that, in any project, external funds represent at least $50 \%$ of total investment. For $m=5$, that percentage equals $80 \%$.
} 
is in Region 2 (rather than in Region 3) or in Region 1 (rather than in Region 2). Increasing $m$ does not affect the pledgeability premium nor the share of investors in $C$ while the economy is within Region 3. This is because in this region investors' segmentation is determined $\theta^{P}$, which does not depend on $m$. Instead, when the economy is within Region 2, investors' segmentation is determined by $\theta^{F}$. Then, an increase in $m$ leads to a reduction in the fraction of investors in $C$. With more investors in the $H$ sector it is then natural to expect that $P$ decreases and that the pledgeability premium, here defined as $\left(1-\frac{P A^{h}}{A^{c}}\right)$, increases. Finally, within Region 1 , investors in the $C$ sector also fall as $m$ increases, but the pledgeability premium is equal to $\left(1-\frac{R}{A^{c}}\right)$ and it does not change with $m$.

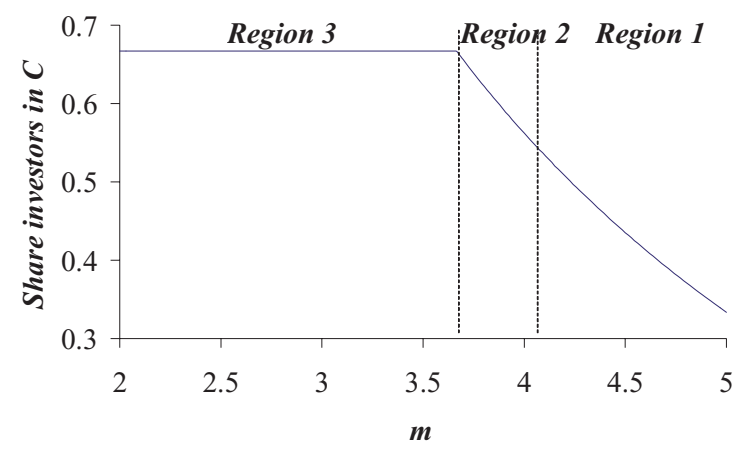

Figure 9. Share of investors in $C$.

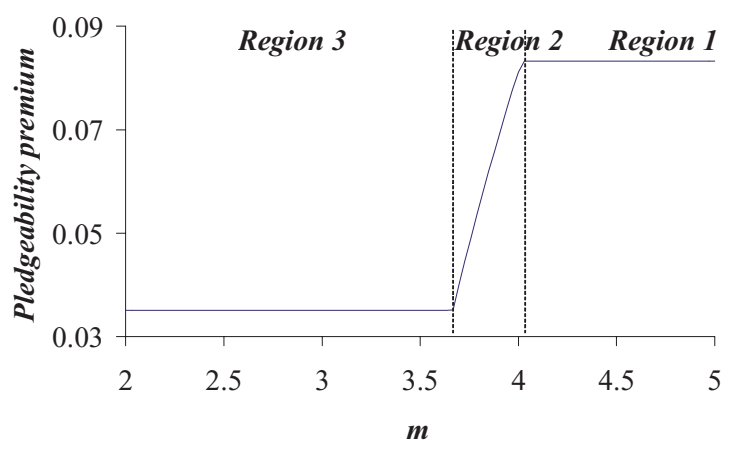

Figure 10. Pledgeability premium.

Figures 11 and 12 show what happens to the share of investors in the $C$ sector and to the pledgeability premium, respectively, when $\theta^{h}$ moves on the interval $[0.8,0.9] .{ }^{27}$ Intuitively, an increase in $\theta^{h}$ constitutes an improvement in the technology to supply houses. Thus, one should expect a fall in $P$ and an increase in the pledgeability premium (except in Region 1 where both the price and the premium do not depend on $\left.\theta^{h}\right) .{ }^{28}$ It also happens that the larger $\theta^{h}$ the more likely the economy's equilibrium is in Region 2 (rather than in Region 3) or in Region 1 (rather than in Region 2). As for the effect of $\theta^{h}$ on the share of investors in the $C$ sector, it is obvious that $\theta^{h}$ does not affect this extensive margin while the economy is within regions 1 and 2 . In these regions the extensive margin is determined by $\theta^{F}$, which does not depend on $\theta^{h}$. Things are slightly more complicated within Region 3. This is because, while the increase in $\theta^{h}$ pushes investors towards the $H$ sector, the fall in $P$ pushes them in the opposite direction. It turns out that, for our calibration, the latter effect dominates so that an increase in $\theta^{h}$ increases the share of investors in the $C$ sector.

\footnotetext{
${ }^{27}$ To illustrate more clearly the impact of $\theta^{h}$ on the share of investors in the $C$ sector and on the pledgeability premium, Figures 11 and 12 were computed for $R=1.07$ since for $R=1.10$ the economy was almost always in Region 1, where $\theta^{h}$ has no effects on those variables.

${ }^{28}$ One could alternatively explain this result simply arguing that increasing $\theta^{h}$ increases the asymmetry in financial conditions across sectors and therefore should lead to an increase in the pledgeability premium.
} 


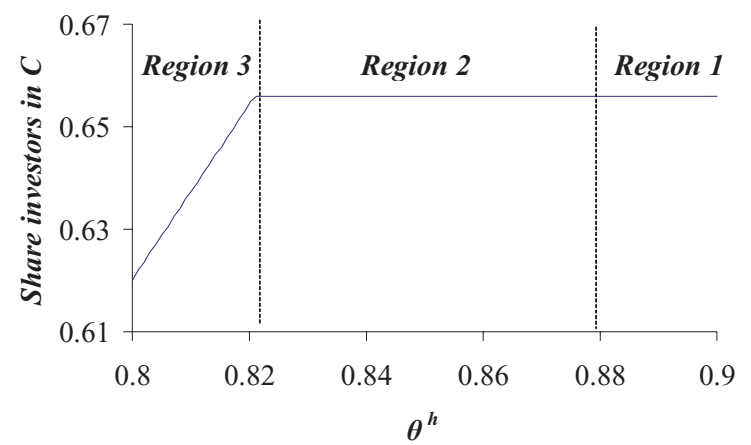

Figure 11. Share of investors in $C$.

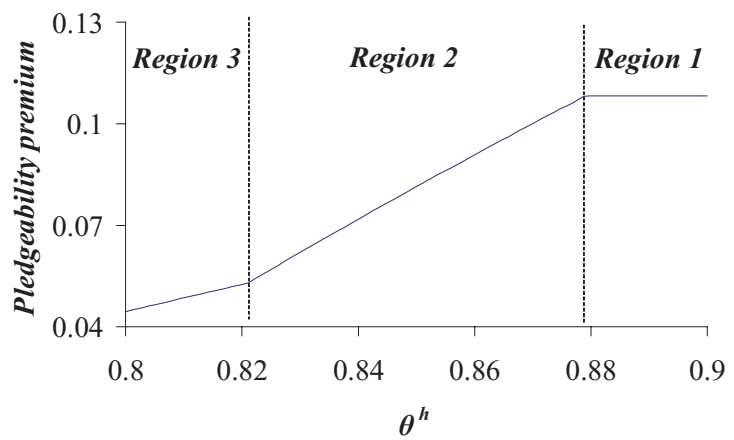

Figure 12. Pledgeability premium.

Figures 13 and 14 show the response of the share of investors in the $C$ sector and of the pledgeability premium, respectively, to changes in $\pi$ within the interval $[30,100]$. These responses are also very intuitive. Increasing $\pi$ implies that the mass of individuals demanding housing increases relative to that of individuals who may supply it. This must lead to an increase in $P$ and to an decrease in the pledgeability premium, as illustrated in Figure 14 (except in Region 1 where the premium is just $\left.1-\frac{R}{A^{c}}\right)$. For a given interest rate, a higher $\pi$ also increases the chance that the economy's equilibrium is in Region 2 (rather than in Region 1) or in Region 3 (rather than in Region 2). Regarding the effect of $\pi$ on the extensive margin, it is obvious that $\pi$ does not affect this margin while the economy is within regions 1 and 2 , but that increases in $\pi$ when the economy is in Region 3 must reduce the share of investors in $C$.

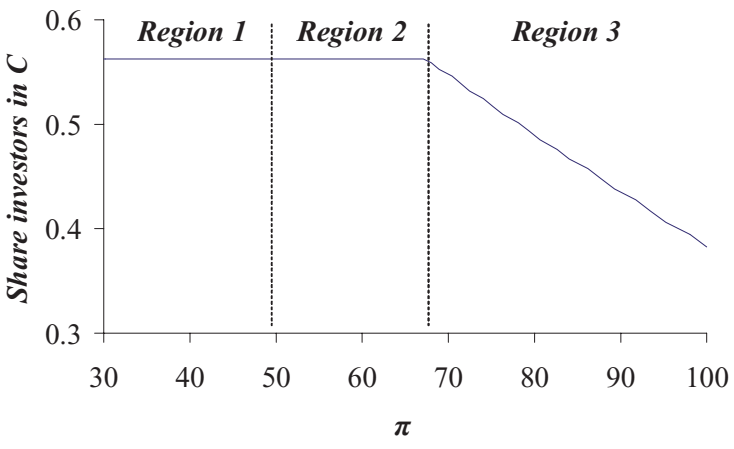

Figure 13. Share of investors in $C$.

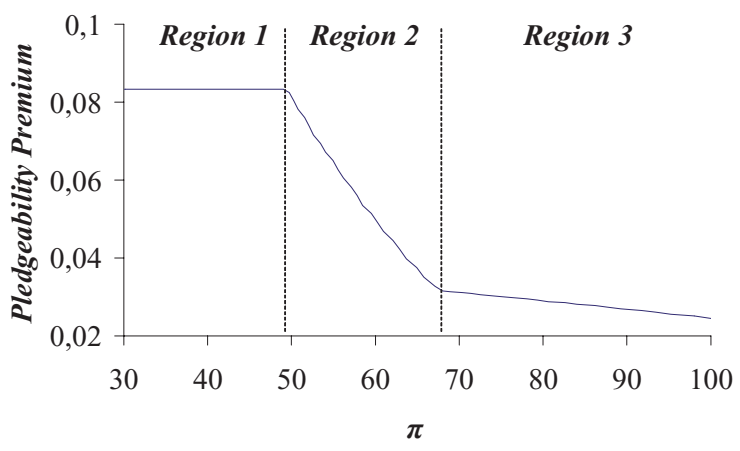

Figure 14. Pledgeability premium.

Finally, Figures 15 and 16 show how changes in $A^{c}$ within the interval $[1.15,1.25]$ affect the share of investors in the $C$ sector and the pledgeability premium, respectively. Increasing $A^{c}$ basically constitutes a positive wealth effect for the economy. Thus, the demand for a nontradeable good such as housing should increase what, keeping the technology to produce houses 
constant, must lead to an increase in $P$. Besides, the larger $A^{c}$ the more likely the economy's equilibrium is in Region 2 (rather than in Region 1) or in Region 3 (rather than in Region 2). The effect of $A^{c}$ on the pledgeability premium is unclear in general, since the premium is defined as $\left(1-\frac{P A^{h}}{A^{c}}\right)$ and both $P$ and $A^{c}$ move in the same direction (obviously, within Region 1, the premium increases with $A^{c}$ ). For our baseline calibration, it turns out that the price effect dominates, so that the higher $A^{c}$ the smaller the premium outside Region 1. The effect of $A^{c}$ on the extensive margin while the economy is within regions 1 and 2 is obvious. This margin is determined by $\theta^{F}$, so that increases in $A^{c}$ increase the share of investors in $C$. Instead, in Region 3, the effect of $A^{c}$ on the extensive margin is ambiguous due to the additional effect on $P$.

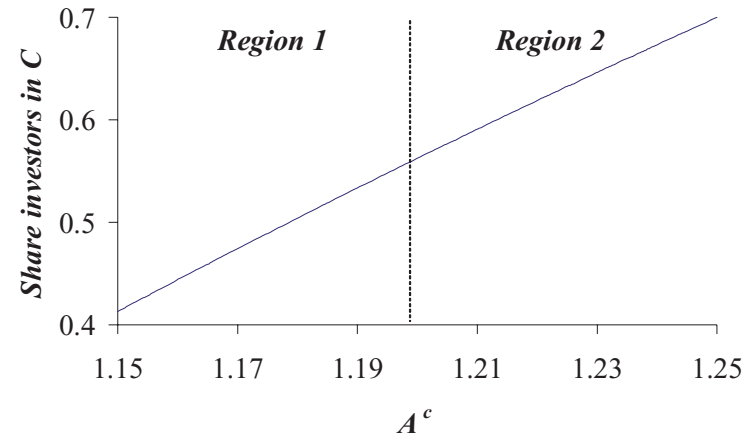

Figure 15. Share of investors in $C$.

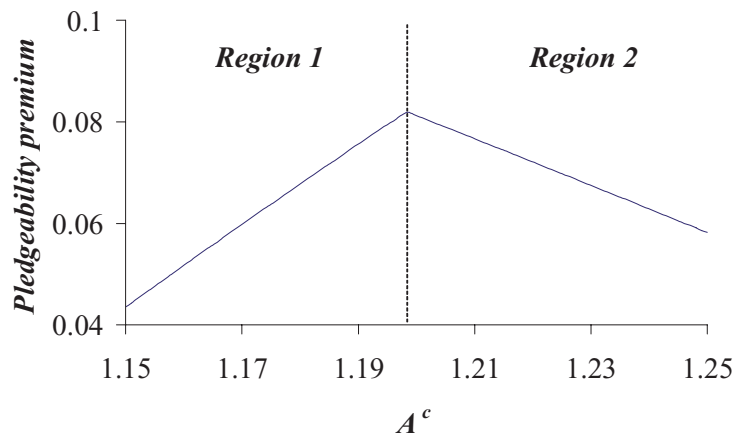

Figure 16. Pledgeability premium.

Although the model in this paper is too stylized to be taken directly to the data, we believe that the exercises presented above may provide useful insights to understand the substantial differences observed across countries in the allocation of investors and production across sectors or in the size of the pledgeability premium. For instance, according to our results, in countries where relatively larger amounts of external funding are required in order to develop an investment project, one should expect that a larger fraction of investors and aggregate investment is placed in the sector with the better financial conditions. Alternatively, in countries where productivity in the consumption goods sector is relatively higher, the share of investors, aggregate investment and production allocated to this sector should be larger. We leave this empirical analysis to a different paper.

\section{$5 \quad$ Final remarks}

How aggregate investment in an economy is allocated across its sectors is a key determinant of, among other things, the economy's aggregate TFP or its future growth prospects. This paper 
has studied how this allocation is conducted when sectors face asymmetric financial conditions. More specifically, we have considered an scenario where investors in some sectors (housing) may provide assets to secure a loan that have more value as collateral than the assets provided by investors in other sectors (consumption). As a result, the former may run projects with higher loan-to-value ratios than the latter.

The differences in ability to raise external financing across sectors affect investors' decisions regarding where to invest. Investors care about total rents (unit rents $\times$ project size) and face a trade-off. While they may run larger projects in the sector with the better financial conditions, unit rents in this sector are lower due to a pledgeability premium. The level of interest rates affects this trade-off. When interest rates are high, projects are small and the differences in unit rents across sectors dominate the differences in project sizes. The marginal investor is the one who can exactly raise the external funds needed to meet the minimum size requirement in the consumption sector. The allocation of investors across sectors is driven by feasibility. Instead, when interest rates are low, projects are large. However, they are much larger in the housing sector than in the consumption sector due to better financial conditions in the former. In this case, the differences in project sizes across sectors dominate the differences in unit rents and some investors who can afford investing in the consumption sector prefer to invest in housing where they can obtain larger rents by running much larger projects. In this case, the feasibility constraint does not play any role and profitability drives the investors' equilibrium segmentation.

Moreover, the effect of interest rates on investors' allocation is non-monotonic. When that allocation is driven by feasibility, a drop in interest rates alleviates the investors' feasibility constraint and allows some investors to leave the housing sector towards the consumption goods sector. Instead, when investors' segmentation across sectors is driven by profitability a drop in interest rate reinforces the effect of the better financial conditions in the housing sector and leads to a reallocation of investors towards that sector. As a result, there is a hump-shaped relationship between interest rates and the share of investors in the consumption goods sector. More importantly, this hump-shaped relationship may translate into a similar hump-shaped relationship between interest rates and the ratio of aggregate investment across sectors, which goes in line with the empirical evidence discussed in the Introduction. A model that considers symmetric financial conditions across sectors, instead, can not generate this non-monotonic relationship.

Overall, we believe that the mechanism highlighted in this paper provides important insights to understand some of the recent macroeconomic phenomena observed in OECD countries. Mainly, how low real interest rates resulted in a boom in investment led by an increase in share of investment in housing (and how this coincided, in some countries, with a stagnant or relatively low productivity growth). 
In our model interest rate drops lead to a boom in the consumption goods sector when interest rates are high and to a boom in housing when interest rate are low. But there is no growth in steady state. Extending the model to allow for steady state growth could deliver interesting implications. In particular, if one believes that the housing sector has low growth potential relative to the consumption goods sector, it could happen that a sustained housing boom is harmful for the economy in the long-run in the sense that it could eventually lead it to a balance growth path exhibiting lower growth. We leave this issue for further research.

\section{References}

[1] ANTRÀS, P., and R. CABALLERO (2007). Trade and Capital Flows: A Financial Frictions Perspective, mimeo.

[2] CORDEN, W. M. (1984). "Booming Sector and Dutch Disease Economics: Survey and Consolidation", Oxford Economic Papers, 36 (3), pp. 359-380.

[3] DAVIS, M. A., and F. ORTALO-MAGNE (2007). Household Expenditures, Wages, Rents, CESifo Working Paper No. 2156.

[4] DRUDI, F., et al. (2007). Corporate Finance in the Euro Area - Including Background Material, ECB Occasional Paper No. 63.

[5] MAtsuyama, K. (2007a). "Credit Traps and Credit Cycles", American Economic Review, 97 (1), pp. 503-516.

[6] - (2007b). Aggregate Implications of Credit Market Imperfections, NBER Working Paper No. 13209.

[7] VAN NIEUWERBURGH, S., and P. O. WEILL (2006). Why Has House Price Dispersion Gone Up?, NBER Working Paper No. 12538. 


\section{BANCO DE ESPAÑA PUBLICATIONS}

\section{WORKING PAPERS ${ }^{1}$}

0721 CLAUDIA CANALS, XAVIER GABAIX, JOSEP M. VILARRUBIA AND DAVID WEINSTEIN: Trade patterns, trade balances and idiosyncratic shocks.

0722 MARTÍN VALLCORBA AND JAVIER DELGADO: Determinantes de la morosidad bancaria en una economía dolarizada. El caso uruguayo.

0723 ANTÓN NÁKOV AND ANDREA PESCATORI: Inflation-output gap trade-off with a dominant oil supplier.

0724 JUAN AYUSO, JUAN F. JIMENO AND ERNESTO VILLANUEVA: The effects of the introduction of tax incentives on retirement savings.

0725 DONATO MASCIANDARO, MARÍA J. NIETO AND HENRIETTE PRAST: Financial governance of banking supervision.

0726 LUIS GUTIÉRREZ DE ROZAS: Testing for competition in the Spanish banking industry: The Panzar-Rosse approach revisited.

0727 LUCÍA CUADRO SÁEZ, MARCEL FRATZSCHER AND CHRISTIAN THIMANN: The transmission of emerging market shocks to global equity markets.

0728 AGUSTÍN MARAVALL AND ANA DEL RÍO: Temporal aggregation, systematic sampling, and the Hodrick Prescott filter

0729 LUIS J. ÁLVAREZ: What do micro price data tell us on the validity of the New Keynesian Phillips Curve?

0730 ALFREDO MARTÍN-OLIVER AND VICENTE SALAS-FUMÁS: How do intangible assets create economic value? An application to banks.

0731 REBECA JIMÉNEZ-RODRÍGUEZ: The industrial impact of oil price shocks: Evidence from the industries of six OECD countries.

0732 PILAR CUADRADO, AITOR LACUESTA, JOSÉ MARÍA MARTíNEZ AND EDUARDO PÉREZ: El futuro de la tasa de actividad española: un enfoque generacional.

0733 PALOMA ACEVEDO, ENRIQUE ALBEROLA AND CARMEN BROTO: Local debt expansion... vulnerability reduction? An assessment for six crises-prone countries.

0734 PEDRO ALBARRÁN, RAQUEL CARRASCO AND MAITE MARTÍNEZ-GRANADO: Inequality for wage earners and self-employed: Evidence from panel data.

0735 ANTÓN NÁKOV AND ANDREA PESCATORI: Oil and the Great Moderation.

0736 MICHIEL VAN LEUVENSTEIJN, JACOB A. BIKKER, ADRIAN VAN RIXTEL AND CHRISTOFFER KOK-SØRENSEN: A new approach to measuring competition in the loan markets of the euro area.

0737 MARIO GARCÍA-FERREIRA AND ERNESTO VILLANUEVA: Employment risk and household formation: Evidence from differences in firing costs.

0738 LAURA HOSPIDO: Modelling heterogeneity and dynamics in the volatility of individual wages.

0739 PALOMA LÓPEZ-GARCÍA, SERGIO PUENTE AND ÁNGEL LUIS GÓMEZ: Firm productivity dynamics in Spain.

0740 ALFREDO MARTÍN-OLIVER AND VICENTE SALAS-FUMÁS: The output and profit contribution of information technology and advertising investments in banks.

0741 ÓSCAR ARCE: Price determinacy under non-Ricardian fiscal strategies

0801 ENRIQUE BENITO: Size, growth and bank dynamics.

0802 RICARDO GIMENO AND JOSÉ MANUEL MARQUÉS: Uncertainty and the price of risk in a nominal convergence process.

0803 ISABEL ARGIMÓN AND PABLO HERNÁNDEZ DE COS: Los determinantes de los saldos presupuestarios de las Comunidades Autónomas.

0804 OLYMPIA BOVER: Wealth inequality and household structure: US vs. Spain.

0805 JAVIER ANDRÉS, J. DAVID LÓPEZ-SALIDO AND EDWARD NELSON: Money and the natural rate of interest: structural estimates for the United States and the euro area.

0806 CARLOS THOMAS: Search frictions, real rigidities and inflation dynamics.

0807 MAXIMO CAMACHO AND GABRIEL PEREZ-QUIROS: Introducing the EURO-STING: Short Term INdicator of Euro Area Growth.

0808 RUBÉN SEGURA-CAYUELA AND JOSEP M. VILARRUBIA: The effect of foreign service on trade volumes and trade partners.

0809 AITOR ERCE: A structural model of sovereign debt issuance: assessing the role of financial factors.

0810 ALICIA GARCÍA-HERRERO AND JUAN M. RUIZ: Do trade and financial linkages foster business cycle synchronization in a small economy?

0811 RUBÉN SEGURA-CAYUELA AND JOSEP M. VILARRUBIA: Uncertainty and entry into export markets.

0812 CARMEN BROTO AND ESTHER RUIZ: Testing for conditional heteroscedasticity in the components of inflation.

0813 JUAN J. DOLADO, MARCEL JANSEN AND JUAN F. JIMENO: On the job search in a model with heterogeneous jobs and workers.

0814 SAMUEL BENTOLILA, JUAN J. DOLADO AND JUAN F. JIMENO: Does immigration affect the Phillips curve? Some evidence for Spain.

0815 ÓSCAR J. ARCE AND J. DAVID LÓPEZ-SALIDO: Housing bubbles.

1. Previously published Working Papers are listed in the Banco de España publications catalogue. 
0816 GABRIEL JIMÉNEZ, VICENTE SALAS-FUMÁS AND JESÚS SAURINA: Organizational distance and use of collateral for business loans.

0817 CARMEN BROTO, JAVIER DÍAZ-CASSOU AND AITOR ERCE-DOMÍNGUEZ: Measuring and explaining the volatility of capital flows towards emerging countries.

0818 CARLOS THOMAS AND FRANCESCO ZANETTI: Labor market reform and price stability: an application to the Euro Area.

0819 DAVID G. MAYES, MARÍA J. NIETO AND LARRY WALL: Multiple safety net regulators and agency problems in the EU: Is Prompt Corrective Action partly the solution?

0820 CARMEN MARTÍNEZ-CARRASCAL AND ANNALISA FERRANDO: The impact of financial position on investment an analysis for non-financial corporations in the euro area.

0821 GABRIEL JIMÉNEZ, JOSÉ A. LÓPEZ AND JESÚS SAURINA: Empirical analysis of corporate credit lines.

0822 RAMÓN MARÍA-DOLORES: Exchange rate pass through in New Member States and candidate countries of the EU.

0823 IGNACIO HERNANDO, MARÍA J. NIETO AND LARRY D. WALL: Determinants of domestic and cross-border bank acquisitions in the European Union.

0824 JAMES COSTAIN AND ANTÓN NÁKOV: Price adjustments in a general model of state-dependent pricing.

0825 ALFREDO MARTÍN-OLIVER, VICENTE SALAS-FUMÁS AND JESÚS SAURINA: Search cost and price dispersion in vertically related markets: the case of bank loans and deposits.

0826 CARMEN BROTO: Inflation targeting in Latin America: Empirical analysis using GARCH models.

0827 RAMÓN MARÍA-DOLORES AND JESÚS VAZQUEZ: Term structure and the estimated monetary policy rule in the eurozone.

0828 MICHIEL VAN LEUVENSTEIJN, CHRISTOFFER KOK SØRENSEN, JACOB A. BIKKER AND ADRIAN VAN RIXTEL: Impact of bank competition on the interest rate pass-through in the euro area.

0829 CRISTINA BARCELÓ: The impact of alternative imputation methods on the measurement of income and wealth: Evidence from the Spanish survey of household finances.

0830 JAVIER ANDRÉS AND ÓSCAR ARCE: Banking competition, housing prices and macroeconomic stability.

0831 JAMES COSTAIN AND ANTÓN NÁKOV: Dynamics of the price distribution in a general model of state-dependent pricing.

0832 JUAN A. ROJAS: Social Security reform with imperfect substitution between less and more experienced workers.

0833 GABRIEL JIMÉNEZ, STEVEN ONGENA, JOSÉ LUIS PEYDRÓ AND JESÚS SAURINA: Hazardous times for monetary policy: What do twenty-three million bank loans say about the effects of monetary policy on credit risktaking?

0834 ENRIQUE ALBEROLA AND JOSÉ MARÍA SERENA: Sovereign external assets and the resilience of global imbalances.

0835 AITOR LACUESTA, SERGIO PUENTE AND PILAR CUADRADO: Omitted variables in the measure of a labour quality index: the case of Spain.

0836 CHIARA COLUZZI, ANNALISA FERRANDO AND CARMEN MARTÍNEZ-CARRASCAL: Financing obstacles and growth: An analysis for euro area non-financial corporations.

0837 ÓSCAR ARCE, JOSÉ MANUEL CAMPA AND ÁNGEL GAVILÁN: Asymmetric collateral requirements and output composition.

\begin{tabular}{|r|c|}
\hline & Unidad de Publicaciones \\
BANCODE ESPAÑ & Alcalá, 522; 28027 Madrid \\
Eurosistema & Telephone +34 91 338 6363. Fax +34913386488 \\
& e-mail: publicaciones@bde.es \\
www.bde.es
\end{tabular}

